\title{
Potential Roles of Sestrin2 in Alzheimer's Disease: Antioxidation, Autophagy Promotion, and Beyond
}

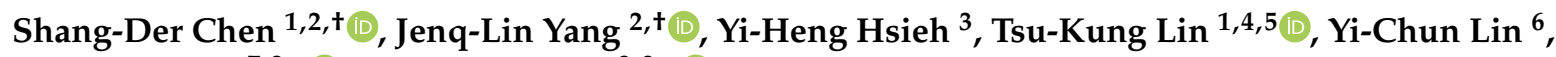 \\ A-Ching Chao $7,8, *(1)$ and Ding-I Yang $3,9, *$ (i)
}

1 Department of Neurology, Kaohsiung Chang Gung Memorial Hospital, Kaohsiung City 83301, Taiwan; chensd@adm.cgmh.org.tw (S.-D.C.); tklin@adm.cgmh.org.tw (T.-K.L.)

2 Institute for Translation Research in Biomedicine, Kaohsiung Chang Gung Memorial Hospital, Kaohsiung City 83301, Taiwan; jyang@adm.cgmh.org.tw

3 Institute of Brain Science, National Yang Ming Chiao Tung University, Taipei City 11221, Taiwan; p400540226@gmail.com

4 College of Medicine, Chang Gung University, Taoyuan City 33302, Taiwan

5 Center for Mitochondrial Research and Medicine, Kaohsiung Chang Gung Memorial Hospital, Chang Gung University College of Medicine, Kaohsiung City 80708, Taiwan

6 Department of Neurology, Taipei City Hospital, Taipei City 10629, Taiwan; DAB16@tpech.gov.tw

7 Department of Neurology, College of Medicine, Kaohsiung Medical University, Kaohsiung City 80708, Taiwan

8 Department of Neurology, Kaohsiung Medical University Hospital, Kaohsiung City 80756, Taiwan

9 Brain Research Center, National Yang Ming Chiao Tung University, Taipei City 11221, Taiwan

* Correspondence: achch@cc.kmu.edu.tw (A.-C.C.); diyang@ym.edu.tw (D.-I.Y.);

Tel.: +886-7-3121101 (A.-C.C.); Tel.: +886-2-28267386 (D.-I.Y.)

+ Authors contributed equally to the work.

Citation: Chen, S.-D.; Yang, J.-L.; Hsieh, Y.-H.; Lin, T.-K.; Lin, Y.-C.; Chao, A.-C.; Yang, D.-I. Potential Roles of Sestrin2 in Alzheimer's Disease: Antioxidation, Autophagy Promotion, and Beyond. Biomedicines 2021, 9, 1308. https://doi.org/ $10.3390 /$ biomedicines 9101308

Academic Editor: Lorenzo Falsetti

Received: 29 July 2021

Accepted: 16 September 2021

Published: 24 September 2021

Publisher's Note: MDPI stays neutral with regard to jurisdictional claims in published maps and institutional affiliations.

Copyright: (C) 2021 by the authors Licensee MDPI, Basel, Switzerland. This article is an open access article distributed under the terms and conditions of the Creative Commons Attribution (CC BY) license (https:/ / creativecommons.org/licenses/by/ $4.0 /)$.

\begin{abstract}
Alzheimer's disease (AD) is the most common age-related neurodegenerative disease. It presents with progressive memory loss, worsens cognitive functions to the point of disability, and causes heavy socioeconomic burdens to patients, their families, and society as a whole. The underlying pathogenic mechanisms of $\mathrm{AD}$ are complex and may involve excitotoxicity, excessive generation of reactive oxygen species (ROS), aberrant cell cycle reentry, impaired mitochondrial function, and DNA damage. Up to now, there is no effective treatment available for AD, and it is therefore urgent to develop an effective therapeutic regimen for this devastating disease. Sestrin2, belonging to the sestrin family, can counteract oxidative stress, reduce activity of the mammalian/mechanistic target of rapamycin (mTOR), and improve cell survival. It may therefore play a crucial role in neurodegenerative diseases like AD. However, only limited studies of sestrin 2 and AD have been conducted up to now. In this article, we discuss current experimental evidence to demonstrate the potential roles of sestrin 2 in treating neurodegenerative diseases, focusing specifically on AD. Strategies for augmenting sestrin2 expression may strengthen neurons, adapting them to stressful conditions through counteracting oxidative stress, and may also adjust the autophagy process, these two effects together conferring neuronal resistance in cases of AD.
\end{abstract}

Keywords: Alzheimer's disease; autophagy; mTOR; oxidative stress; sestrin2

\section{Introduction}

Patients with age-related neurodegenerative diseases usually present with a relentlessly deteriorating clinical course. Worst of all, the lack of effective treatment results in heavy socioeconomic burdens to patients, family, and the whole of society [1-3]. Alzheimer's disease (AD), a type of dementia with progressive memory loss and declined cognitive functions, is the most common neurodegenerative disease in the elderly. Based on the information from the World Health Organization (WHO), approximately 50 million people suffer from dementia worldwide, and nearly 10 million new cases are added every year, making the disease one of the main causes of disability and dependence. AD may account 
for $60-70 \%$ of all dementia cases (https:/ / www.who.int/news-room/fact-sheets/detail/ dementia, accessed on 21 September 2020). According to "2021 Alzheimer's disease facts and figures", in the USA [4], approximately 6.2 million senior Americans over 65 years old have AD. By 2060, with a steep projected increase, the number of AD patients may rise to 13.8 million. Data revealed that, from 2000 to 2019, deaths resulting from human immunodeficiency virus (HIV), heart disease, and stroke declined, while deaths from AD increased more than $145 \%$ [4]. The total healthcare costs in 2020 are approximated at $\$ 305$ billion and are expected to increase to more than $\$ 1$ trillion as the population ages [5]. It is crucial to delay, reduce, or prevent the occurrence of disability from $\mathrm{AD}$ and lessen the heavy burden it places on society.

The major pathological hallmarks of AD brains are gross atrophy of the brain, as well microscopically observable senile plaques and neurofibrillary tangles (NFTs) [6-8]. Senile plaques are extracellular structures mainly composed of insoluble deposits of amyloid-beta peptide $(A \beta)$, a peptide fragment of 39-43 amino acids derived from sequential cleavage of the transmembrane protein amyloid precursor protein (APP) by $\beta$ - and $\gamma$-secretase [9-12]. Newly synthesized full-length APP is transported from the endoplasmic reticulum (ER) to the Golgi apparatus (GA)/trans-Golgi network (TGN) for further protein processing and maturation. The acidic environment $(\mathrm{pH}=6.0-6.5)$ in the TGN or the late GA is optimal for the activity of many processing enzymes, including BACE1. The full-length APP delivered to the plasma membrane may be subjected to non-amyloidogenic cleavage by $\alpha$ - and then $\gamma$-secretase to release the soluble APP-alpha (sAPP $\alpha$ ), the p3 fragment, and the APP intracellular domain (AICD). Alternatively, a portion of the full-length APP may also be endocytosed into early endosomes and possibly rerouted to the acidic recycling endosomes (REs), where BACE1 resides, to produce $A \beta$ [13]. In addition, extracellular $A \beta$ can also be taken up through receptor binding and subsequently internalized, thereby leading to its accumulation within various intracellular compartments, including endosomes, multivesicular bodies (MVBs), lysosomes, mitochondria, the ER, the TGN, and cytosol [14].

$\mathrm{A} \beta$ can induce neurotoxicity through various mechanisms, such as excitotoxicity [15], excessive generation of reactive oxygen species (ROS) [16], aberrant cell cycle reentry [17,18], impaired mitochondrial function [19], and DNA damage [20], all of these mechanisms together contributing to neuronal damage or even death. Moreover, $\mathrm{A} \beta$ can also alter gene transcription [19], and thereby affect protein expression, which may influence the survival or death of neuronal cells in AD-related pathophysiology.

Maintenance of neuronal functions depends on axonal transport of proteins, organelles, and vesicles from the soma to the nerve terminals [21]. Going the other way, neurotrophic factors, including the members of the neurotrophin family, secreted from postsynaptic targets must be transmitted retrogradely from nerve terminals via axonal transport back to the soma [22]. Thus, failure of axonal transport may contribute to neuronal death. As a microtubule-binding protein important for microtubule assembly and stabilization, hyperphosphorylation of tau compromises its biological functions and destabilizes the structures of microtubules, and is accompanied by disturbance to axonal transport [23]. Furthermore, increasing evidence suggests that $A \beta$ may also disrupt axonal transport and contribute to $\mathrm{AD}$ pathophysiology [21].

It was proposed two decades ago that fibrils may not be the only toxic form of $A \beta$; small oligomers of $A \beta$, or $A \beta$-derived diffusible ligand (ADDL), and $A \beta$ protofibrils may also have potent neurotoxicity [24]. Like $A \beta$ oligomers, tau oligomers formed during the early stages of aggregation are also pathologically relevant to the loss of neurons and behavioral impairments in several neurodegenerative disorders called tauopathies, the most common of which is $\mathrm{AD}$ [25]. In addition to the aggregation of extracellular amyloid plaques, emerging evidence has revealed the crucial role of intraneuronal amyloid species (iA $\beta$ s) which can appear in the membrane or the lumen of late endosomes and precede further aggregation, eventually accumulating inside the endosome or endolysosome $[26,27]$. It was also noted that, besides the extracellular aggregation of homologous $\mathrm{A} \beta$ species, cross-seeding of different amyloid proteins, or even between different misfolded proteins, 
such as $A \beta s$ and tau, may be biologically significant, and even critical in the progression of $\mathrm{AD}$ [28]. Apart from cross-seeding, crosstalk between $\mathrm{A} \beta$ and tau may also play a vital role contributing to $\mathrm{AD}$ pathogenesis. For example, $\mathrm{A} \beta$ has been shown to trigger alternative splicing of tau isoforms via glycogen synthase kinase-3beta (GSK-3 $\beta$ ), making tau more susceptible to hyperphosphorylation [29,30]. Overall, these effects could further aggravate aberrant cellular signaling, induce excessive tau phosphorylation, worsen toxic tau accumulation, and lead to synapto/neurotoxic effects [26]. A simplified cartoon summarizing the pathogenic mechanisms of AD is shown in Figure 1, below.

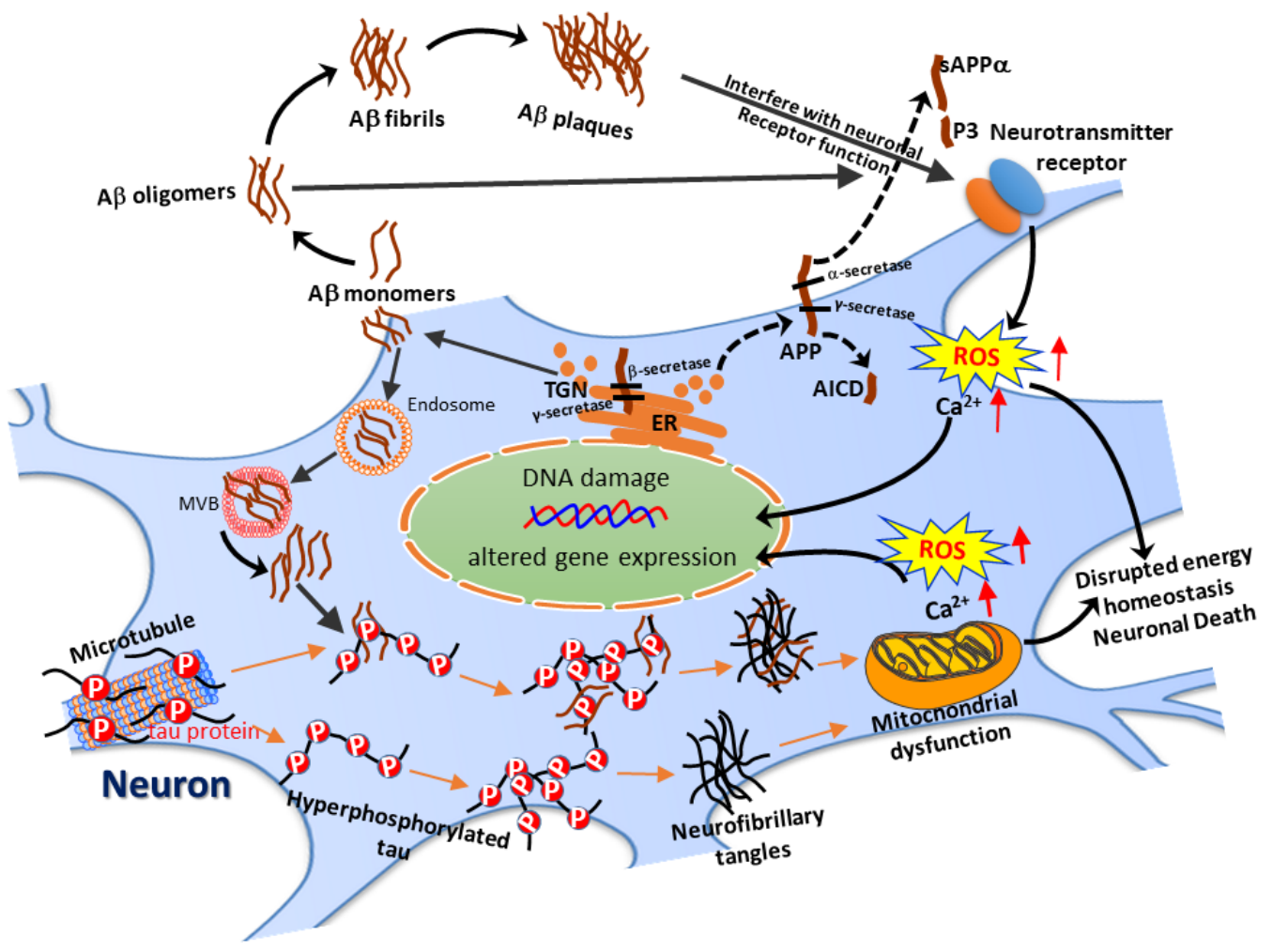

Figure 1. The cartoon diagram demonstrates the pathogenic processes of amyloid-beta peptide (A $\beta)$ and tau protein. Through the amyloidogenic pathway, the full-length amyloid precursor protein (APP) is sequentially cleaved by $\beta$-secretase (encoded by beta-site amyloid precursor protein cleaving enzyme-1 or BACE1) and $\gamma$-secretase to generate A $\beta$. Newly synthesized APP is transported from the endoplasmic reticulum (ER) to the Golgi apparatus (GA) for protein maturation. The acidic $\mathrm{pH}$ in the trans-Golgi network (TGN) or the late GA is optimal for BACE1 activity, with production of secreted $\mathrm{A} \beta$; the sequential amyloidogenic cleavages of full-length APP by $\beta$ - and $\gamma$-secretase also generate soluble APP-beta (sAPP $\beta$ ) and the APP intracellular domain (AICD), though these are not depicted in the diagram. A portion of the full-length APP reaching the plasma membrane may be subjected to the non-amyloidogenic cleavage by $\alpha$ - and then $\gamma$-secretase to release the soluble APP-alpha (sAPP $\alpha$ ), the p3 fragment, and the AICD. Another portion of the full-length APP may also be endocytosed into early endosomes and possibly be rerouted to the acidic recycling endosomes (REs; not depicted), where BACE1 resides, for intracellular production of $A \beta$. Furthermore, extracellular $A \beta$ can also be taken up through receptor binding and subsequent internalization, resulting in its accumulation within various intracellular compartments, including endosomes, multivesicular bodies (MVBs), and mitochondria (not depicted). The extracellular $A \beta$ monomers aggregate into oligomers and then into fibrils, eventually forming senile plaques. Tau protein is a microtubule-binding protein, which is hyperphosphorylated in AD neurons. The phosphor-tau monomer may also aggregate into tau oligomers and, finally, into neurofibrillary tangles (NFTs). The intraneuronal A $\beta$ species also oligomerize or even mix with tau proteins to form mixed aggregates. The extracellular senile plaques, 
the extracellular and intraneuronal $\mathrm{A} \beta$ oligomers, as well as tau oligomers and NFTs, together lead to excessive production of reactive oxygen species (ROS), $\mathrm{Ca}^{2+}$ overload, mitochondrial dysfunction, and disrupted energy homeostasis, ultimately causing neuronal death. In addition to those pictured above, other pathogenic mechanisms are not demonstrated in this figure due to limited space. For example, loss of tau binding destabilizes microtubules, thus compromising anterograde axonal transport of proteins, mitochondria, and vesicles from soma to the nerve terminals, which may negatively impact nerve transmission. Conversely, neurotrophic factors, especially neurotrophins, secreted from target cells also fail to be retrogradely transported from the nerve terminal back to the soma to nourish the neurons, also leading to neuronal demise. Please see the text for more details.

Sestrins, including sestrin1, sestrin2, and sestrin3, belong to a group of highly evolutionarily conserved proteins in mammalian cells, and may play a crucial role in stressful conditions, such as oxidative stress, hypoxia, and DNA damage [31-34]. While the structures of sestrin 1 and sestrin 3 await further elucidation, the essential characteristics of sestrin2 have been gradually revealed in recent years [35,36]. Three distinctive functional sites were identified, which are critical for inhibition of ROS production, modulation of the mammalian/mechanistic target of rapamycin (mTOR) complex 1 (mTORC1), and for leucine-binding $[35,36]$. Inhibiting either ROS for antioxidation or mTORC1 for autophagy promotion may attenuate degenerative processes associated with aging [35]. Therefore, sestrins may possess two beneficial effects that are pivotal for anti-aging $[37,38]$.

Despite the potential effect of sestrins on age-related neurological disorders, only quite limited studies about AD have been reported. We have shown in a previous study that sestrin 2 was induced by $A \beta$ in primary rat cortical neurons and an increased expression of sestrin 2 was also found in the cortices of 1-year-old AD transgenic mice [39]. We also showed that sestrin 2 functions as an endogenous protective mediator against $A \beta$-induced neurotoxicity, in part through enhancement of autophagy activity [39]. In another recent study, we further demonstrated that $\mathrm{A} \beta$-induced sestrin 2 expression contributes to antioxidative activity in neurons; furthermore, $A \beta$ induction of sestrin 2 is at least partly mediated by the activation of transcription factors NF-kB and p53 [40]. In this review article, we discuss recent progress in revealing the underlying molecular mechanisms concerning the sestrin2-mediated protective effects against neuronal dysfunction in AD. Better understanding of the potential novel pathway in AD may guide further research into developing effective therapeutic regimens in the future. Finding the way to augmenting sestrin2 expression may have significant clinical implications, especially in treating many devastating neurodegenerative diseases, including AD.

\section{The Biological Roles of Sestrin2}

Sestrins, including sestrin1, sestrin2, and sestrin3, belong to a gene family and function as stress-inducible proteins that affect metabolism through perceiving nutrient status and redox level in living organisms. Sestrin1 (also known as PA26) was initially discovered in human Saos-2 osteosarcoma cells as one of the p53-induced transcripts and was mapped to chromosome 6q21 through a differential display screening [34,41]. Sestrin1 is ubiquitously expressed in most tissues, including lung, kidney, pancreas, skeletal muscle, and brain tissues [33], and it can be activated under oxidative stress and irradiation in a p53-dependent fashion [34,42]. Sestrin2 (also known as Hi95), located in chromosome 1p35.3, was first discovered in glioblastoma cells under prolonged hypoxia and its transcription was found to be increased following DNA damage [33]. Later, it was noted that sestrin1 and sestrin2, through activating the AMP-dependent kinase (AMPK) pathway, may affect tuberous sclerosis complex 2 (TSC2) expression to inhibit mTOR-mediated cell over-proliferation [43]. Sestrin3, located in chromosome 11q21, was identified from database mining of the PA26related gene family [32,33]. mRNA expression of these sestrin genes is presented diffusely during mouse embryogenesis and also in adult tissues at various levels [32]. Sestrin1 is robustly expressed in the brain, heart, liver, and skeletal muscle; sestrin 2 is expressed more 
in the kidney, leucocytes, lungs, and liver; sestrin3 is expressed at higher levels in the brain, kidney, small intestine, and skeletal muscle [32,34,44].

It has been revealed that the crystal structure of human sestrin2 (hSesn2) has distinct globular subdomains, each possessing separate functions [35]. As shown below in Figure 2A, the N-terminal domain (Sesn-A) diminishes alkyl hydroperoxide radicals through the helix-turn-helix oxidoreductase motif. Mutations of Cys125, His132, and Tyr127, which are, respectively, the catalytic cysteine, the residue critical for the conserved proton relay system, and the residue potentially involved in the catalytic process, reduce this redox activity. The C-terminal domain (Sesn-C) of hSesn2, whose sequence is highly conserved across the sestrin family, has lost its antioxidant activity but acquired another important function in mTORC1 inhibition via physical association with GTPase-activating protein activity toward the Rags-2 (GATOR2) complex, in which process Asp406 and Asp407 (the DD motif) are vital. Furthermore, the DD motif is involved in activation of AMP-dependent protein kinase (AMPK), which is also important for mTORC1 inhibition. Besides GATOR2 binding and AMPK activation for mTOR inhibition, sestrin2 may also carry the guanosine nucleotide dissociation inhibition (GDI) function. However, mutation studies of Arg419/Lys422/Lys426 in Sesn-C suggested that whether these amino acid residues are truly critical for GDI functions is still in question [35].

The availability of amino acids is critical for the regulation of protein synthesis in living organisms. Leucine, one of the essential amino acids, is indispensable for this process and, more importantly, leucine was found to be crucial for mTORC1 activation in cells [45]. Located in the Sesn-C of hSesn2 (Figure 2A), charged residues Glu451 and Arg390, from two sides of a single binding pocket, anchor leucine in place through salt bridges with the free amine and carboxyl groups, respectively, whereas the isopropyl side chain of the bound leucine forms extensive hydrophobic interactions with residues Leu389, Trp444, and Phe447 in the pocket. In addition to contacting the charged sides and hydrophobic base of the pocket, three threonine residues (Thr374, Thr377, and Thr386) are positioned directly above the leucine to form a "lid" that encloses the top of the leucine, thereby locking the ligand in place [36]. As a leucine sensor, sestrin2 inhibits mTORC1 activity through the Rag guanosine triphosphatases (GTPase) and its regulators-GATOR1 and GATOR2. Thus, the binding of leucine with sestrin2 disrupts the connection of sestrin2 with GATOR2, allowing GATOR2 to enhance mTORC1 activity [36]. It has previously been demonstrated that adult sestrin 2 gene knockout mice subject to a fasting/refeeding regimen or maintained with a high-fat diet suffered from various metabolic derangements, such as hepatosteatosis, insulin resistance, and glucose intolerance, with increased ROS extent and mTORC1 activity [38,46].

Despite the availability of the crystal structure of hSesn2, the detailed molecular information for sestrin 1 and sestrin 3 remains to be fully elucidated. However, sequence alignment of the three human sestrins revealed an overall $44.8 \%$ amino acid sequence identity [47]. Furthermore, the amino acid residues critical for alkyl hydroperoxidase activity (Cys125, His132, and Tyr127), GATOR2-binding and AMPK activation for mTORC1 inhibition (Asp406 and Asp407), and leucine-binding (Glu451 and Arg390; Leu389, Trp444, and Phe447; Thr374, Thr377, and Thr386) are all evolutionarily conserved in the three human sestrins. It is therefore reasonable to speculate that hSesn 1 and hSesn 3 may share most, if not all, of the functional roles of hSesn2. However, as compared with sestrin2, the potential involvement of sestrin 1 and sestrin 3 in nervous systems has been studied much less well. Below, in Figure 2B, is the list of known biological functions of all three sestrins. 
A

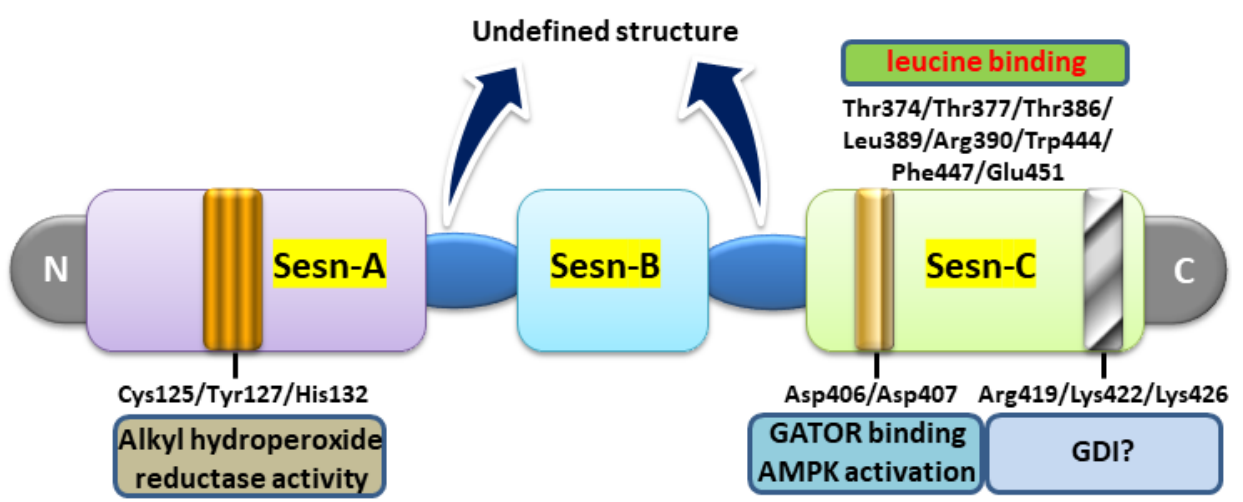

B

\begin{tabular}{|l|l|}
\hline \multicolumn{1}{|c|}{ Functions of sestrin family } & \multicolumn{1}{c|}{ Individual sestrin } \\
\hline $\begin{array}{l}\text { As an intracellular leucine sensor to negatively } \\
\text { regulate the mTORC1 signaling pathway }\end{array}$ & sestrin1, sestrin2, sestrin3 \\
\hline $\begin{array}{l}\text { Protection against oxidative and genotoxic } \\
\text { stresses through AMPK and mTOR inhibition }\end{array}$ & sestrin1, sestrin2, sestrin3 \\
\hline $\begin{array}{l}\text { Promoting p62-dependent autophagic } \\
\text { degradation of Keap1 to activate Nrf2 }\end{array}$ & sestrin1, sestrin2 \\
\hline \begin{tabular}{l} 
Alkyl hydroperoxide reductase activity \\
\hline $\begin{array}{l}\text { Regeneration of peroxiredoxin } \\
\text { To regulate the insulin-receptor signaling } \\
\text { pathway through activation of mTORC2 }\end{array}$
\end{tabular} & sestrin1, sestrin2 \\
\hline
\end{tabular}

AMPK: AMP-activated protein kinase

Keap1: Kelch-like ECH-associated protein 1

mTORC1: mechanistic target of rapamycin kinase complex I

mTORC2: mechanistic target of rapamycin kinase complex 2

Nrf2: nuclear factor erythroid 2-related factor 2

Figure 2. The structural and functional domains as well as the biological functions of three sestrin members. (A) The strip diagram illustrates the three major structural domains (Sesn-A, Sesn-B, and Sesn-C). Cys125/Tyr127/His132, located within the Sesn-A domain, is critical for alkyl hydroperoxidase activity. The Asp406/Asp407 residues, the so-called "DD motif", located within Sesn-C are vital for GATOR2 binding and AMPK activation, both contributing to mTORC1 suppression. The leucine binding pocket spanning from Thr374 to Glu451 in the Sesn-C is also important for amino acid sensing and mTOR regulation. The guanosine nucleotide dissociation inhibition (GDI) domain containing Arg419/Lys422/Lys426 is also shown in Sesn-C. Based on the crystal structure, however, whether these amino acid residues are critical for GDI functions remains questionable. All the information was based on Kim et al., 2015 [35] and Saxton et al., 2016 [36]. (B) Potential biological functions of three sestrins are listed. Information was derived from UniProt (https:/ / www.uniprot.org) for human sestrin1 [UniProtKB-Q9Y6P5 (SESN1_HUMAN)], human sestrin2 [UniProtKB-P58004 (SESN2_HUMAN), human sestrin3 [UniProtKB-P58005 (SESN3_HUMAN)], and mouse sestrin3 [UniProtKB- Q9CYP7 (SESN3_MOUSE)].

Expression of the sestrin 2 genes is regulated by several critical transcription factors, enabling the cells to cope with various stressful insults. Initially the crucial role of the p53 tumor suppressor in regulating the expression of sestrin 2 under hypoxic and genotoxic stress was revealed [33]. Later, additional studies revealed further transcription factors that are critical for the expression of sestrin 2 under a variety of stressful conditions. Oxidative stress can activate the nuclear factor erythroid 2-related factor-2 (Nrf2) to regulate sestrin2 
expression $[48,49]$. Hypoxia may induce sestrin2 expression where hypoxia-inducible factor-1 (HIF-1) may play a certain role [33,50-52], although the detailed mechanism is not well understood. In our earlier study [53], we found that brain-derived neurotrophic factor (BDNF) induced sestrin2 expression, which required dimerization of nuclear factor$\kappa B(N F-\kappa B)$ subunits p65 and p50. Further, BDNF also enhanced production of nitric oxide (NO), formation of $3^{\prime}, 5^{\prime}$-cyclic guanosine monophosphate (cGMP), and activation of cGMP-dependent protein kinase (PKG). Indeed, BDNF induced nuclear translocation of PKG-1 and its direct interaction with p65/p50 to form a ternary complex, thereby leading to heightened NF- $\mathrm{KB}$ binding to the sestrin2 gene promoter with resultant upregulation of its mRNA and proteins [53]. Apart from PKG/NF- $\mathrm{B}$, BDNF has also been shown to induce sestrin2 in neurons by activating transcription factor-4 (ATF4) [54]. In another recent study [40], we also found that NF- $\mathrm{kB}$ and p53 are involved in A $\beta$-induced sestrin2 expression in primary cortical neurons. Additional regulatory mechanisms responsible for sestrin2 induction under various stressful or physiological conditions may emerge in the near future

Nutrients including amino acids, lipids, and glucose are crucial for the biosynthetic processes in the cell. An inadequate supply of nutrients can seriously modify cellular metabolism. Sestrin 2 activation may serve as one of the metabolic accommodations to nutrient deficiency in cells [38]. Glucose starvation, inhibition of glycolysis, and impairment of mitochondrial respiration can disrupt energy production, leading to the activation of two transcription factors, ATF4 and Nrf2, that can bind directly to the consensus sequences within the promoter to induce sestrin2 gene transcription [49,55-57]. ATF4 is also involved in the induction of sestrin2 as a result of a deficiency in amino acid supply in mouse embryonic fibroblasts [58]. The inadequacy of growth factors may result in the expression of sestrin2. It has been demonstrated in cancer cells that serum deprivation can activate the c-Jun N-terminal kinase (JNK) pathway and upregulate sestrin2 expression, which could be abolished by specific siRNAs against JNK1/2 or c-Jun [59]. Various physiological and pathological conditions, such as excessive ROS generation, ischemia, $\mathrm{Ca}^{2+}$ dyshomeostasis, and inflammatory response can all cause an accumulation of misfolded proteins in the endoplasmic reticulum (ER), with resultant ER stress [60]. ER stress may lead to cellular dysfunction and/or cell death and contributes to the progression of many diseases. Modulation of ER stress pathways may represent a potential therapeutic strategy. It was reported that activating transcription factor-6 (ATF6)-dependent sestrin2 induction can lessen the severity of ER stress-mediated liver injury [61]. In another study, it was shown that the hepatoprotective role of sestrin2 against chronic ER stress depends on the regulation of CCAAT-enhancer-binding protein-beta (c/EBP $\beta$ ) [62]. Together, these previous reports identify the crucial roles played by sestrin 2 in dealing with various cellular stresses under diverse physiological and pathological conditions. A simplified diagram (Figure 3) demonstrates that distinct transcription factors are activated under a variety of stressful conditions, thereby leading to induction of sestrin 2 expression, which can regulate autophagy and contribute to antioxidation. 


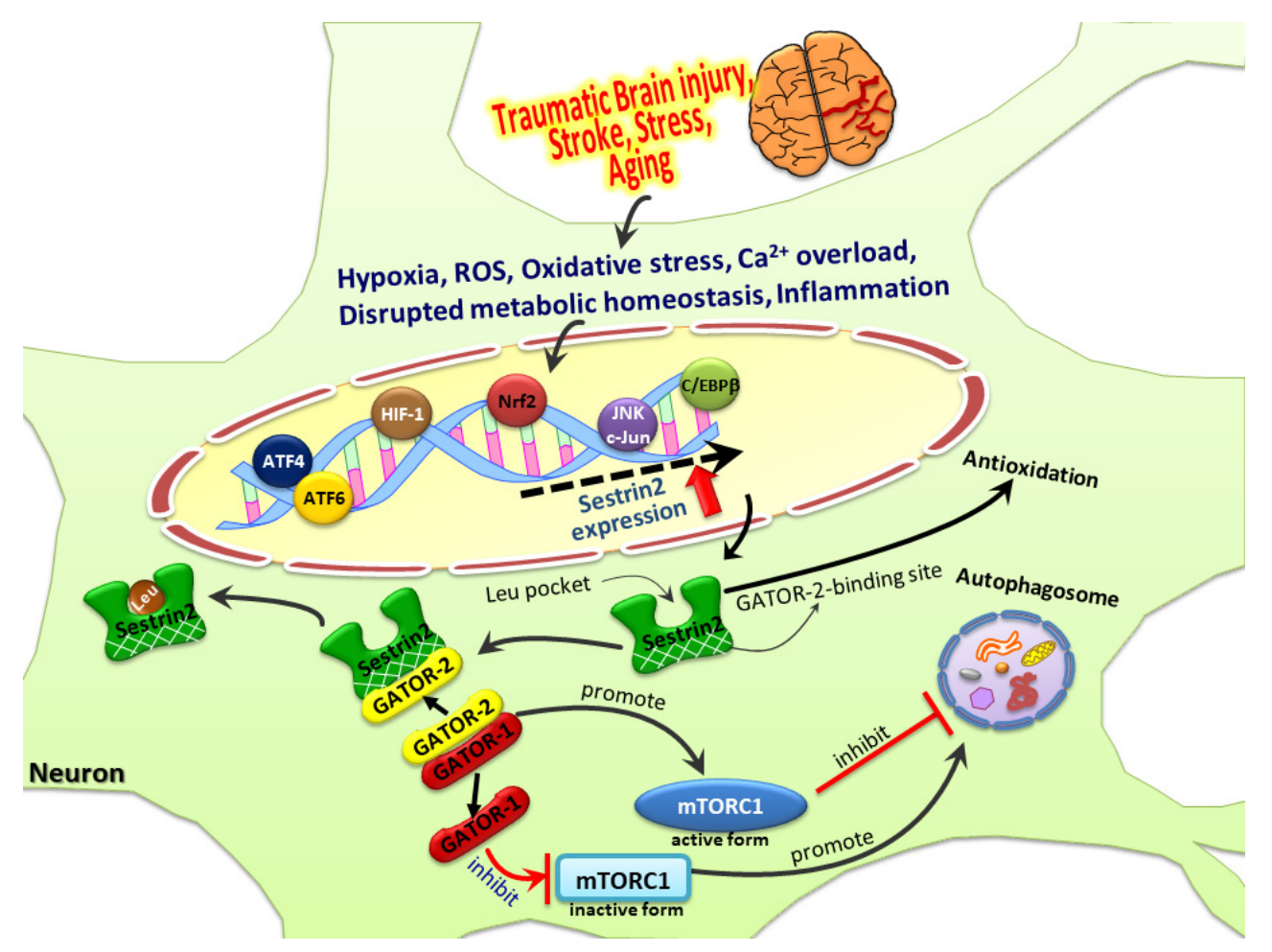

Figure 3. Brain trauma, stroke, neurological disorders, and aging induce hypoxia, the production of reactive oxygen species (ROS), $\mathrm{Ca}^{2+}$ overload, metabolic dyshomeostasis, and neuronal inflammation. Subsequently, the injury-induced signaling pathways promote sestrin2 expression via the activation of various transcription factors (which particular factors depending on which stressors), such as transcription factor-4 (ATF4), ATF6, hypoxia-inducible factor-1 (HIF-1), nuclear factor erythroid 2-related factor-2 (Nrf2), c-Jun N-terminal kinase (JNK)/c-Jun, and CCAAT-enhancer-binding proteinbeta $(C / E B P \beta)$. Sestrin2, as a sensor for essential amino acids with a leucine-binding pocket, also has a binding site for the GTPase-activating protein activity toward Rags-2 (GATOR2). In the presence of sufficient amino acids available for protein synthesis, sestrin 2 may bind to leucine and release the bound GATOR2. The freed GATOR2 can then physically associate with GATOR1, which can no longer bind to, and hence inhibit, $\mathrm{mTORC}$, thereby promoting protein synthesis while inhibiting autophagy. Under the stressful condition in which amino acids are insufficient, binding of GATOR2 to sestrin2 allows GATOR1 to inhibit mTORC1, thereby promoting autophagy while inhibiting protein synthesis. In addition to regulating autophagy and protein synthesis via binding with leucine or GATOR2, the endogenous alkyl hydroperoxidase activity of sestrin2 also exerts direct antioxidative actions.

\section{Sestrin2 in Age-Related Clinical Conditions}

Persuasive evidence supports the notion that aging is related to various harmful mechanisms, such as escalation of oxidative stress, instability of genetic materials, declined protein homeostasis, impaired mitochondrial function, increased cellular senescence, and stem cell exhaustion [63]. The accumulation of various cellular damages among tissues in aging organisms leads eventually to functional breakdown, causing disability or death. Therefore, aging is believed to be a risk factor for various disorders, such as cardiovascular diseases, stroke, type II diabetes, cancers, and neurodegenerative diseases [63-65]. Inhibition of either ROS production or mTORC1 activation may counteract aging [35], and as sestrin2 is characterized by both these functions, it may exert such beneficial effects [66,67]. In fact, enhancement of sestrin2 expression reduces aging markers. Conversely, lessening sestrin2 expression accelerates aging processes [68].

Aging is a predetermined time-related deterioration in various physiological conditions, and is a critical risk factor for cancer development. Cancer and aging involve similar processes of progressive time-dependent cellular damage. As sestrin2 is critically involved 
in aging [38,67], it may play a pivotal role in cancer progression, and is regarded as a potential tumor suppressor. In non-small cell lung cancer patients, higher sestrin2 expression was a favorable prognostic factor, while lower sestrin 2 expression was accompanied by poor tumor cell differentiation, as well as more advanced staging in terms of tumor, node, and metastasis (TNM) [69]. It was shown that colorectal cancer patients with lower expression of sestrin2 showed poor prognostic outcomes [70]. Docosahexaenoic acid (DHA) can increase oxaliplatin-induced autophagic cell death through the ER stress/sestrin2 pathway in colorectal cancer [71], whereas downregulation of sestrin2 can accelerate colon carcinogenesis [72].

Hypernutrition, causing obesity, hepatosteatosis, and insulin resistance, is related to chronic activation of p70S6 kinase and mTORC1 [73]. Activation of sestrin2 can lower the extents of fatty liver and insulin resistance [73]. Sestrin2 can activate AMPK, inhibit mTORC1 activity, and maintain a high AKT level to suppress the extent of gluconeogenesis in the liver, thereby reducing the level of blood sugar. Sestrin2-deficient obese mice were found to present an evident decline of AKT activity, leading to insulin resistance and a higher level of glucose production [73]. In a recent study, serum levels of sestrins are significantly decreased in patients with diabetes and dyslipidemia. It appears that sestrin2 levels are robustly associated with diabetes, dyslipidemia, atherosclerosis, and the atherogenic index [74]. Declined serum sestrin2 levels were also observed in diabetic patients with nephropathy, particularly in those with macroalbuminuria [75].

It was demonstrated previously that loss of dSestrin (the only one sestrin homologue in Drosophila) results in age-associated pathologies, including cardiac dysfunction, muscle degeneration, and triglyceride accumulation. The cardiac dysfunction showed reduced heart rate and compromised heart function. The detrimental effects induced by dSestrin deficiency were generally inhibited by AICAR and rapamycin, the AMPK activator and the mTORC1 inhibitor, respectively [67]. These results indicate that the sestrin family may play crucial roles in the pathophysiology of cardiac regulation [76]. In a recent review article, sestrin2 is considered a rising star among antioxidants, with future therapeutic potential for reducing heart injury induced by oxidative stress, promoting cell survival through the activation of Nrf2/AMPK, and inhibiting mTORC1 to combat various cardiovascular diseases, such as cardiomyopathy, heart failure, and myocardial infarction [77]. Despite these promises, however, the occurrence of major adverse cardiac events is predicted in patients with chronic heart failure who have higher plasma sestrin2 concentrations [78]. The conflicting results as far as the beneficial or detrimental effects of sestrin2 in heart failure are concerned await further clarification.

Stroke is the most common age-related cerebral vascular disease and the chief cause of physical and intellectual disability in adults, as well as the leading cause of mortality in developed countries [79]. Several studies have investigated the roles of sestrin2 in cerebral ischemia [80-83]. It was demonstrated that sestrin2 can activate the Nrf2/heme oxygenase-1 (HO-1) pathway, leading to augmentation of angiogenesis following focal cerebral ischemia [82]. Another study also showed the critical role of sestrin2 in promoting angiogenesis in focal cerebral ischemia by activating the Nrf2/p62 pathway [81]. In contrast, silencing sestrin 2 expression may reduce mitochondrial activity, suppress mitochondrial biogenesis, and ultimately exacerbate cerebral ischemia/reperfusion injury by preventing the AMPK/PGC-1 $\alpha$ pathway [83]. Although sestrin2 seems to have pro-survival characteristics in the context of ischemic brain injury, the anti-inflammatory role of sestrin 2 is unknown. In a recent study, it was demonstrated that sestrin 2 exerts neuroprotective effects by changing microglial polarization and mitigating the extent of inflammation in the ischemic mouse brain, which may be due to the inhibition of the mTOR pathway and the restoration of autophagic flux [80]. It is to be expected that knowledge of the mechanisms underlying additional protective effects of sestrin2 may emerge in the not too distant future. 


\section{Potential Roles of Sestrin2 in Age-Related Neurodegenerative Diseases: Focusing on $\mathrm{AD}$}

As mentioned above, the sequences of the critical amino acid residues important for known biological activities of hSesn2, including alkyl hydroperoxide reductase, mTORC1 inhibition, and leucine binding, are also conserved in hSesn 1 and hSesn3. However, the crystal structures of sestrin 1 and sestrin 3 are still not available. Nevertheless, there are a few studies implicating sestrin 1 and sestrin 3 in nervous system disorders. For example, sestrin1 may exert protective effects in oxygen-glucose deprivation/reoxygenation (OGD/R)induced neuronal injury, a cellular model for mimicking cerebral ischemia/reperfusion injury in vitro [84]. Furthermore, sestrin 3 has been identified as a pro-convulsant gene network in the human epileptic hippocampus [85]. Results derived from sestrin 3 knockout rats also suggested that sestrin3 may increase the occurrence and/or severity of seizures [86]. Conversely, silencing rno-miR-155-5p in vivo mitigated the pathophysiological features associated with the status epilepticus, which was accompanied by attenuation of apoptosis in the hippocampus, by enhancing expression of sestrin 3 in rats, implying that sestrin 3 plays a beneficial role in offsetting temporal lobe epilepsy [87]. Further dissection of the pathophysiological roles of sestrin 1 and sestrin 3 will require a greater understanding of their molecular structures, as well as the upstream regulatory mechanisms involved in their expression in nervous systems.

Among age-related disorders, chronic neurodegenerative diseases are particularly concerning due to the lack of efficacious treatments, their irremediable clinical course, and their association with substantial social-economic burdens [1-3]. The potential roles of sestrin2 in combatting neurodegenerative diseases, including AD, Parkinson's disease (PD), and Huntington's disease (HD), while still awaiting further evidence, have gradually been recognized in recent years.

It is widely accepted that maintaining proper levels of reactive nitrogen species and ROS are crucial for ensuring regular neuronal function [88]. Yet, excessive ROS generation with heightened levels of oxidation in lipids, proteins, and DNA, or inherent lower antioxidant competence in the brain, may have detrimental effects on the organism and play a role in the pathophysiology of various chronic neurodegenerative diseases, including AD, PD, and HD [89,90]. Numerous mechanisms underlie oxidative stressmediated neurodegeneration; these include calcium overload, glutamate excitotoxicity, inflammation, functional impairment of mitochondria, and apoptotic processes [88]. The ability to lessen these harmful effects may be the key to developing effective treatments for neurodegenerative diseases.

As mentioned above, sestrin2, with its dual functions, can directly reduce oxidative stress through restoring overoxidized peroxiredoxins, and indirectly lessen oxidative stress through regulating mTOR to augment the activity of autophagy, or specifically, mitophagy, to remove the worn-out or damaged mitochondria with higher levels of electron leakage and hence free radical production. The N-terminal domain of sestrin2 decreases oxidative stress by its helix-turn-helix motif, while the C-terminal domain of sestrin 2 may physically associate with GATOR2, thereby causing the inhibition of mTORC1 [35]. Apart from the effect of oxidative stress, one more common pathogenic mechanism in chronic neurodegeneration is the deposition of aberrant and/or misfolded proteins, such as $A \beta$ and tau protein in AD, Lewy body (LB) in PD, and mutant huntingtin in HD. Enhancing the activity of autophagy may help to eradicate neuronal dysfunction induced by misfolded proteins, thereby opening an opportunity towards developing a new therapeutic strategy for treating neurodegenerative diseases [91]. The dual biological functions of sestrin2, with increasing antioxidative ability and autophagy-promoting activity to eliminate aggregated proteins and damaged mitochondria, give this molecule a unique position in protecting neurons against degeneration.

$\mathrm{PD}$ is the second most common aging-related neurodegenerative disease that mainly presents syndromes with slow movements, tremors, and rigidity. The underlying cause of PD is not well understood but may involve various genetic and environmental fac- 
tors [92]. The main pathological feature of PD is LB, which is composed of ubiquitin-bound, misfolded $\alpha$-synuclein protein in the dopamine neurons in the substantia nigra of the midbrain $[93,94]$. In an in vitro PD model with 1-methyl-4-phenylpyridinium $\left(\mathrm{MPP}^{+}\right)$, it was revealed that $\mathrm{MPP}^{+}$neurotoxicity increases sestrin2 expression, whereas downregulation of sestrin2 with small interference RNA augments $\mathrm{MPP}^{+}$-related neurotoxicity in SH-SY5Y cells [95]. In another in vivo PD model induced by rotenone, sestrin2 exerts a protective effect over dopaminergic neurons against rotenone-induced neurotoxicity by activating an AMPK-dependent autophagy pathway [96]. In a clinical study, serum sestrin2 levels were found to be elevated in PD patients compared to controls [97]. In postmortem human samples, it was found that PD patients had higher expression levels of sestrin2 in the midbrain [95].

No report was available concerning HD and sestrin2 either in the clinical or pre-clinical studies. 3-Nitropropionic acid (3-NP) can inhibit the function of the mitochondrial respiratory complex II (also named succinate dehydrogenase), decrease ATP production, impair cellular energy metabolism, aggravate the extent of oxidative stress, cause mitochondrial DNA damage, and thus impair the function of mitochondria [98,99]. Although genetic models of HD are more popular due to their similarity to the phenotypes observed in HD, 3-NP is still a useful model to study neurotoxic phenomena, mitochondrial alterations, and neuroprotective effects for HD patients [100]. Therefore, 3-NP has been used as a pharmacological model to study neurodegeneration and neuronal death involving mitochondrial dysfunction in HD [101]. Despite the indirect relationship, we have shown that BDNF protects 3-NP-induced oxidative stress through augmenting sestrin2 expression. Furthermore, BDNF induction of sestrin2 implicates the NO/PKG/NF- $\mathrm{B}$ pathway [53]. This study thus highlights the probable beneficial role of sestrin 2 in this devastating hereditary neurodegenerative disease. Understanding the potential role of sestrin 2 in impeding HD pathogenesis may require further investigation into the genetic models of HD, such as R6/2 or other knock-in mice.

$\mathrm{AD}$ is the most common age-related neurodegenerative disease involving various pathogenic mechanisms such as excitotoxicity, excessive generation of ROS, aberrant cell cycle reentry, impaired mitochondrial function, and DNA damage [15-19]. Although emerging roles of sestrin2 in various neurological diseases have been suggested before [102], limited studies concerning sestrin2 and AD have been reported [39,40,103-107]. In a 2003 study, in which human neuroblastoma CHP134 cells were analyzed with cDNA microarray technology with confirmation by semi-quantitative RT-PCR, it was revealed that sestrin2 is overexpressed under treatment of $A \beta$ [107]. Furthermore, in human neuroblastoma SH-SY5Y cells, A $\beta 1-42$ dose-dependently enhanced sestrin2 expression, whereas cotreatment with atorvastatin reversed sestrin 2 back to the control level [103]. We have also demonstrated, in primary cortical neurons, that both $A \beta 25-35$ and $A \beta 1-42$ triggered the expression of sestrin2 $[39,40]$, as is discussed in more detail below. In addition to these pre-clinical studies, the first human study reported in 2012 using postmortem brain tissues from advanced AD patients with immunohistochemistry findings showed intense sestrin2 expression in the neuropil, which may suggest a diffuse expression in various components among neurons, glia, and vascular cells. Using double-labeling immunofluorescence microscopy, co-localization between phosphorylated tau and sestrin 2 is observed in the neurons and the neurites in neurofibrillary lesions [106]. These findings together implied that sestrin2 is expressed at least in the neurons of AD patients. Another clinical study demonstrated significant overexpression of sestrin 2 protein and mRNA in the serum of AD patients as compared to the mild cognitive impairment (MCI) and the age-matched control groups. A difference in serum sestrin2 concentration between MCI and the control groups was also evident. However, no significant difference in sestrin1 levels was observed among the study groups. These results therefore suggested the potential role of sestrin2 as a biomarker in the analysis of peripheral blood in AD patients, and highlighted the importance of sestrin2, as opposed to sestrin1, in the progression of AD [104]. Despite these arguments supporting the important roles of sestrin2 in AD, it should be noted 
that, with similar biological functions and significantly conserved amino acid sequences identified across the different members of the sestrin family, although potential involvements of sestrin 1 and sestrin 3 in AD have not been reported, they certainly cannot be overlooked. Overall, this review has only focused on discussing the potential roles of sestrin2 in neurodegenerative disorders, AD in particular.

We have explored the potential link between sestrin2 and A $\beta$-induced neurotoxicity $[39,40]$. In an in vitro study, we demonstrated that sestrin 2 was induced by A $\beta$ s, including both $A \beta 25-35$ and $A \beta 1-42$, in primary culture of fetal rat cortical neurons. We further showed an in vivo result of increased sestrin 2 expression in the aged APPswe/PSEN1dE9 transgenic mice. More importantly, sestrin 2 functions as an endogenous protective moderator, through the adjustment of autophagy, against A $\beta$-induced neurotoxicity [39]. It is well known that sestrin 2 has an antioxidant character and plays a critical role in agerelated diseases [66]. In our recent report [40], A $\beta$-induced sestrin2 expression in primary cortical neurons was found to have an antioxidant effect, resulting in the suppression of $A \beta$-mediated ROS production, enhancement of lipid peroxidation, and formation of 8-hydroxy-2-deoxyguanosine (8-OH-dG) as an index of oxidative DNA damage. Interestingly, we found that lentivirus-mediated overexpression of the N-terminal domain of sestrin2 in primary cortical neurons completely blocked A $\beta 25-35$-induced ROS production, whereas overexpression of the C-terminal domain partially, but statistically significantly, suppressed ROS formation. Although the sestrin2 C-terminal domain is known to have the capability of inhibiting mTORC1 to promote autophagy [35], we speculated that augmentation of autophagy with enhanced removal of damaged mitochondria, or mitophagy, may also contribute to the antioxidant function of sestrin2. Upstream of sestrin2, we found that the observed $A \beta$ effect on sestrin 2 expression is at least partially mediated by $p 53$ and NF- $\kappa B$. Indeed, apart from regulating sestrin 2 induction, $\mathrm{p} 53$ and NF- $\kappa B$ subunits p65/p50 also affect the expression of each other [40]. Furthermore, upstream of p53 and NF-kB, we identified at least two signaling pathways, namely nitric oxide synthase/cGMP-dependent protein kinase (NOS/PKG) and phosphatidylinositol 3-kinase (PI3K)/ Akt, that may have contributed to the observed $A \beta$ induction of sestrin2 in cortical neurons [40]. A diagram summarizing our findings is shown in Figure 4, below.

The synaptic activity of neurons can affect the homeostasis of $A \beta$ and tau. Both are aggregated and accumulated during the progression of $\mathrm{AD}$ and are critical for neuronal function. Furthermore, impairment of synaptic activity is linked with AD [108]. Physiologic synaptic activity, through NMDA receptor signaling, can enhance antioxidant activity and increase sestrin 2 expression to exert a protective effect through transcription factor C/EBPbeta [109]. Presenilin proteins are catalytic components of $\gamma$-secretase involved in various functions such as proteolytic cleavage of the Notch and APP, adjustment of neurotransmitter release, and are vital for the survival of neurons in aging [110]. Mutations of the presenilin genes are one of the main causes of familial AD [111]. Impairment of presenilin activity may compromise synaptic functions, resulting in neurodegeneration and ultimately dementia [112]. It was demonstrated that cells deficient in presenilin have lower levels of sestrin 2 and are accompanied with mTORC1 dysregulation. These findings show that sestrin2, through attenuation of oxidative stress and its nutrient-sensing ability via mTOR, plays a critical role in AD-related conditions [105].

Emerging evidence suggested the potential benefit of sestrin2 in AD. Medications with the capability to alter sestrin 2 expression may therefore have the potential to prevent or delay the clinical deterioration of this neurodegenerative disease. It was previously shown that atorvastatin reduces $A \beta$-induced synaptotoxicity and memory impairment through a p38MAP kinase pathway [113]. Atorvastatin could also activate autophagy through AMPK/mTOR signaling $[113,114]$. In a recent study, it was demonstrated that sestrin 2 and the autophagy marker LC3II were increased with $\mathrm{A} \beta$ treatment in human neuroblastoma cells; co-treatment of atorvastatin and $A \beta$ reduced oxidative stress and decreased sestrin2 expression [103]. We have shown before that BDNF can induce sestrin2 expression in rat primary cortical neurons and exert a protective effect against 3-NP neurotoxicity by 
reducing the production of free radicals [53]. BDNF is known to protect against $A \beta$-induced neurotoxicity in vitro as well as in rodent and primate models $[115,116]$. However, whether sestrin2 induction by BDNF contributes to this neuroprotective effect has not been tested. The possibility certainly cannot, however, be excluded.

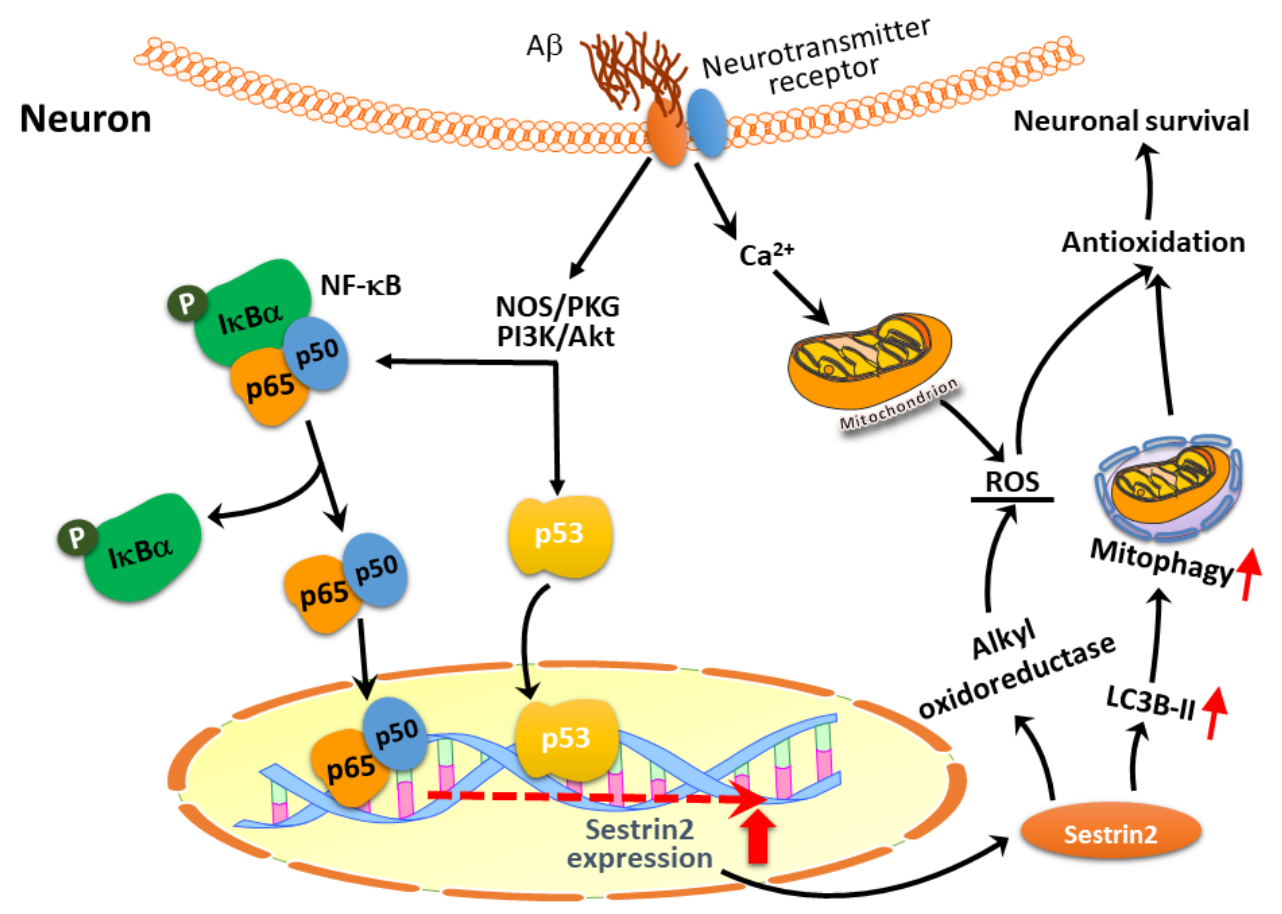

Figure 4. Amyloid-beta peptide $(\mathrm{A} \beta)$ enhances calcium dyshomeostasis and the generation of reactive oxygen species (ROS), thereby leading to oxidative stress with damaged mitochondria. Meanwhile, $\mathrm{A} \beta$ also induces $\mathrm{p} 53$, as well as nuclear factor-kappaB (NF-kB) subunits p65 and p50 via activation of nitric oxide synthase (NOS)/cGMP-dependent protein kinase (PKG) and phosphatidylinositol 3-kinase (PI3K)/Akt. The transcription factors, p50, p65, and p53 translocate into the nucleus of the neuron to promote expression of sestrin 2 mRNA, as indicated by the red dashed arrow. The alkyl hydroperoxidase activity of sestrin 2 may neutralize excessive ROS generated by A $\beta$ with antioxidative functions. In addition, sestrin 2 may trigger autophagy, as is indicated by the conversion of the microtubule-associated protein-1 light-chain 3B-I (LC3B-I) into LC3B-II, and possibly also mitophagy, in order to remove $A \beta$-damaged mitochondria known to produce more ROS. Sestrin2 thus may function as an endogenous protective mediator inducible by $\mathrm{A} \beta$ that contributes to neuronal survival against $A \beta$ neurotoxicity.

In addition to alkyl hydroperoxidase activity and enhanced autophagy to alleviate oxidative stress, sestrin2 may also trigger the Nrf2/ARE pathway to augment antioxidant responses. For example, following photochemical cerebral ischemia in rats, expression of sestrin2, Nrf2, HO-1, and VEGF were significantly increased. Overexpression of sestrin2 by AAV injection further enhanced their expression [82]. In another study of photothrombotic ischemia in rats, sestrin 2 may promote angiogenesis by activating Nrf2 via upregulation of p62 with enhanced interaction between p62 and Keap1, thereby improving the neurological function, reducing brain infarction, and alleviating brain edema [81]. Sestrin2 was also a direct target of microRNA miR-148b-3p in the HT22 hippocampal neurons challenged with OGD/R. Furthermore, Nrf2/ARE was a downstream antioxidant signal contributing to the observed protective effects through miR-148b-3p inhibition, and hence sestrin 2 induction, in response to OGD/R injury [117]. In the $\mathrm{H}_{2} \mathrm{O}_{2}$-stimulated retinal ganglion cells (RGCs), sestrin2 overexpression increased the nuclear translocation of Nrf2, thereby upregulating the Nrf2/ ARE target genes, including HO-1 and NAD(P)H quinone oxidoreductase-1 [118]. As mentioned above, sestrin2 itself may be a downstream target of Nrf2 [48,49]. Although 
these studies were conducted in non-neuronal cells like mammary epithelial cells and hepatocytes, the possibility that Nrf2 activation may induce sestrin 2 expression in the nervous system cannot be excluded. Whether sestrin 2 may trigger its own expression, thereby forming a positive feedforward loop, via Nrf2/ARE in neurons, also requires further investigation. The potential role of sestrin2 in age-related neurodegenerative diseases is demonstrated in Figure 5.

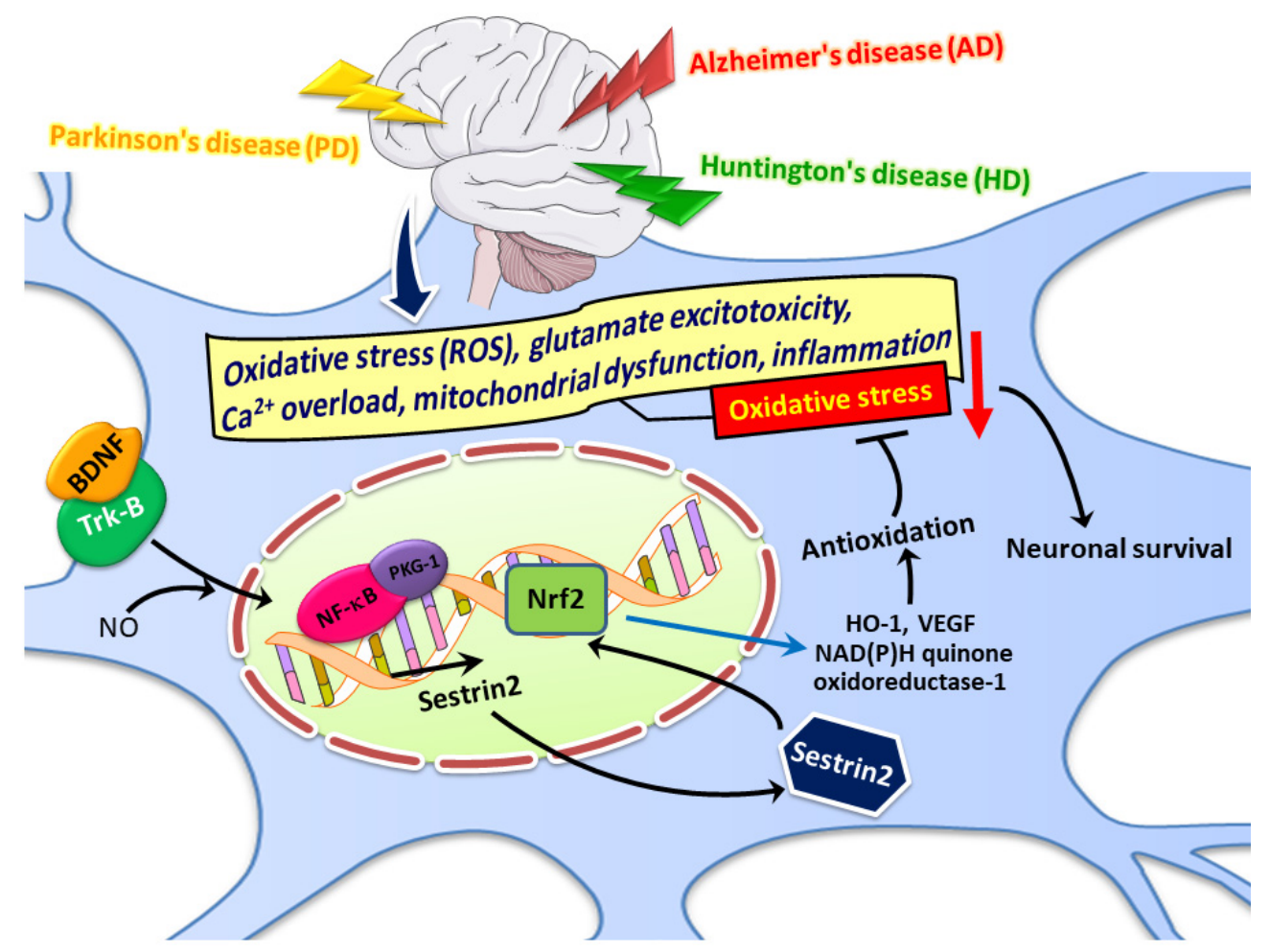

Figure 5. Multiple pathogenic mechanisms including oxidative stress, with excessive production of reactive oxygen species (ROS), glutamate-induced excitotoxicity, calcium overload, mitochondrial dysfunction, and inflammation contribute to neuronal death in various neurodegenerative disorders like Alzheimer's disease (AD), Parkinson's disease (PD), and Huntington's disease (HD). Brainderived neurotrophic factor (BDNF) enhances sestrin2 expression via signaling pathways involving nitric oxide (NO) / $3^{\prime}, 5^{\prime}$-cyclic guanosine monophosphate (cGMP)-dependent protein kinase-1 (PKG1)/nuclear factor-kappaB (NF-kB). In addition to the alkyl hydroperoxidase activity and autophagy promotion, sestrin 2 may also have antioxidant properties by activating nuclear factor erythroid 2-related factor-2 (Nrf2) with enhanced expression of antioxidant proteins like heme oxygenase1 (HO-1), vascular endothelial growth factor (VEGF), and NAD(P)H quinone oxidoreductase-1. These antioxidant proteins then mitigate oxidative stress, as indicated by the red arrow, that is commonly observed in various neurodegenerative diseases. The possibility that BDNF may exert its neuroprotective effects, in addition to its well-known neurotrophic actions, via induction of sestrin2 in various neurodegenerative disorders, requires further investigation.

\section{Medications or Chemical Compounds Capable of Altering Sestrin2 Expression}

The outcomes of clinical trials using drugs to target amyloid and tau have been unsatisfactory up to now, thereby leading to enthusiasm in targeting alternative mechanisms in AD studies $[119,120]$. Drug repurposing involves taking the research into an existing, readyto-use drug and assessing its therapeutic potential with respect to another disease [121,122]. Several well-known success stories include aspirin, sildenafil, and thalidomide [123]. This approach may provide a less expensive and quicker method of drug discovery. Several recent review articles emphasize the clinical potential of drug repurposing in the context of AD [120,124-126]. It would be worthwhile to search among medications with neuroprotec- 
tive effects, as these are likely to have a better chance of achieving clinically meaningful results with neurodegenerative diseases [127]. The potential of certain medications to activate sestrin 2 expression requires further investigation.

Several studies revealed that certain drugs capable of activating sestrin2 expression in various disease models may be worth testing in $\mathrm{AD}$ as well. It was shown that empagliflozin, which is a sodium-glucose cotransporter 2 (SGLT2) inhibitor useful for treating diabetes mellitus (DM) patients, can regulate sestrin2, the AMPK-mTOR pathway, and ROS homeostasis to improve obesity-related cardiac dysfunction in mice [128]. Another study demonstrated that liraglutide, a glucagon-like peptide 1 (GLP-1) agonist for DM patients, may lessen obesity-related fatty liver disease through regulating the sestrin2-mediated Nrf2/HO-1 pathway [129].

5-Fluorouracil is an antimetabolite widely used for chemotherapeutic treatment of cancers $[130,131]$. It was shown that 5-fluorouracil increases sestrin2 levels in a p53-dependent pathway and inhibits cancer cell migration in an in vitro colon cancer study [132]. Nelfinavir, an ER stress-inducing agent, and bortezomib, a proteasome inhibitor, can both enhance sestrin2 expression, which may be useful to treat cancers [133]. Interestingly, nelfinavir inhibited endogenous $A \beta 1-40$ production from primary cultured human cortical neurons [134]. Whether these reagents may also carry therapeutic potential for $\mathrm{AD}$ requires further investigation.

Other chemical compounds such as resveratrol and melatonin possessing pleiotropic effects like antioxidancy or anti-inflammation were studied based on their capability of upregulating sestrin 2 in various disease models [135-137]. Resveratrol is a naturally occurring polyphenol that is abundant in grape seeds and skin [138,139]. It can offer protective effects against various age-related diseases like AD through diverse mechanisms [138,140]. These molecular mechanisms include modulation of NF- $\mathrm{kB}$, regulation of inflammatory cytokines, production of antioxidant enzymes, angiogenesis, apoptosis, lipid metabolism, and mitochondrial biogenesis-all critical for its potential clinical application [141,142]. It was demonstrated before that resveratrol affects sestrin 2 gene induction and inhibits liver $X$ receptor-alpha $(\mathrm{LXR} \alpha)$-mediated hepatic lipogenesis [137]. Methylglyoxal is implicated in the formation of advanced glycation end-products associated with diabetes and age-related neurodegenerative diseases [143]. In a previous study using methylglyoxal to induce cell death in HepG2, a human liver cancer cell line, it was found that resveratrol reduces methylglyoxal-induced mitochondrial impairment and apoptosis through sestrin2 induction [136]. Other flavonoid polyphenols or flavone derivatives, such as eupatilin [144,145], pentamethylquercetin [146], and isorhamentin [147], also possess the capability to alter sestrin2 expression and are worth studying further in AD models.

Melatonin, a molecule widely distributed in living organisms, is involved in various physiological and biological functions among diverse tissues and organs. It possesses prominent antioxidant effects, functions as a free radical scavenger, augments antioxidant enzymes, lessens mitochondrial electron leakage, and reduces pro-inflammatory signaling pathways [148]. These properties of melatonin underline the possibility for future clinical use in numerous disorders, including neurodegeneration [149]. It was shown that melatonin can inhibit proliferation and apoptosis in the vascular smooth muscle through upregulation of sestrin2, which may be important in preventing atherosclerosis and restenosis of vessel lumen [135]. It would be interesting to know the effect of sestrin2 expression under melatonin treatment in a stressful condition, such as in A $\beta$-induced neurotoxicity.

It is believed that a long list of medications, natural products, chemical compounds, or small molecules capable of altering sestrin2 expression may exert beneficial effects over AD-related mechanisms. This awaits further investigation and may lead to more opportunities for treating such devastating neurodegenerative diseases as AD. 


\section{Conclusions and Future Perspectives}

Being a member of the sestrin family, sestrin2 acts as a crucial intracellular detector capable of regulating various biological processes to maintain the homeostasis of living organisms. Emerging evidence reveals that sestrin2 may have beneficial effects for vulnerable cells, such that they may adapt to numerous pathological situations under diverse stressful conditions, including DNA injury, hypoxic state, metabolic dyshomeostasis, and oxidative stress. In age-related neurodegenerative disorders, excessive generation of ROS and dysfunction of autophagy may play pivotal roles in the pathogenesis among these diseases. Sestrin2, with distinctive dual-functional sites to counteract excessive ROS generation and inhibit mTOR activity for autophagy promotion, is presumed to play a crucial role in $\mathrm{AD}$, although at present only limited information is available to firmly establish this notion. Certain medicinal compounds or natural products, such as flavonoid-related products, can alter the expression levels of sestrin2. It is believed that any means of increasing sestrin2 expression may possess significant clinical implications for the abatement of AD-related neurodegeneration. The possibility awaits further investigation. It is uncertain, however, whether the overactivation of sestrin 2 may result in detrimental effects due to autophagic dysfunction. It may be difficult to determine the pros and cons of excessive activation or inhibition of autophagy in terms of neurodegenerative diseases, including AD. This concern further reveals the crucial need for a thorough understanding of both the downstream targets, as well as the upstream regulators, of sestrin2. Fuller elucidation of the signaling pathways of sestrin2 would accelerate the discovery of novel therapies for disease treatment, especially for those diseases with a devastating clinical course, such as AD.

Funding: This study was supported by the Ministry of Science and Technology (MOST) in Taiwan (MOST 104-2314-B-010-014-MY2, MOST 107-2314-B-010-020-MY3, and MOST 109-2314-B-010-038-MY3 to Ding-I Yang; MOST 108-2314-B-037-038-MY3 to A-Ching Chao; MOST 109-2314-B-182A-078-MY3 to Shang-Der Chen; MOST 108-2320-B-182A-005-MY3 to Jenq-Lin Yang), Department of Health in Taipei City Government (11001-62-038 to Ding-I Yang), and Chang Gung Medical Foundation (CMRPG8I0051, CMRPG8I0052, and CMRPG8I0053 to Shang-Der Chen; CMRPG8K0652 to Jenq-Lin Yang). This study was also financially supported by Kaohsiung Medical University Hospital (KMUH109-9R72 to A-Ching Chao) and Brain Research Center, National Yang Ming Chiao Tung University, from The Featured Areas Research Center Program within the framework of the Higher Education Sprout Project by the Ministry of Education (MOE) in Taiwan (110BRC-B407 to Ding-I Yang).

Conflicts of Interest: The authors declare no conflict of interest.

\section{References}

1. Dugger, B.N.; Dickson, D.W. Pathology of Neurodegenerative Diseases. Cold Spring Harb. Perspect. Biol. 2017,9 , a028035. [CrossRef]

2. Takizawa, C.; Thompson, P.L.; van Walsem, A.; Faure, C.; Maier, W.C. Epidemiological and Economic Burden of Alzheimer's Disease: A Systematic Literature Review of Data across Europe and the United States of America. J. Alzheimer's Dis. 2014, 43, 1271-1284. [CrossRef]

3. Hung, C.-W.; Chen, Y.-C.; Hsieh, W.-L.; Chiou, S.-H.; Kao, C.-L. Ageing and neurodegenerative diseases. Ageing Res. Rev. 2010, 9 , S36-S46. [CrossRef]

4. 2021 Alzheimer's disease facts and figures. Alzheimer's Dement. 2021, 17, 327-406. [CrossRef] [PubMed]

5. Economic burden of Alzheimer disease and managed care considerations. Am. J. Manag. Care 2020, 26, S177-S183. [CrossRef] [PubMed]

6. DeTure, M.A.; Dickson, D.W. The neuropathological diagnosis of Alzheimer's disease. Mol. Neurodegener. 2019, 14, 32. [CrossRef]

7. Jack, C.R., Jr.; Bennett, D.A.; Blennow, K.; Carrillo, M.C.; Dunn, B.; Haeberlein, S.B.; Holtzman, D.M.; Jagust, W.; Jessen, F.; Karlawish, J.; et al. NIA-AA Research Framework: Toward a biological definition of Alzheimer's disease. Alzheimer's Dement. 2018, 14, 535-562. [CrossRef] [PubMed]

8. Murphy, M.P.; LeVine, H., III. Alzheimer's Disease and the Amyloid- $\beta$ Peptide. J. Alzheimer's Dis. 2010, 19, 311-323. [CrossRef] [PubMed]

9. O’Brien, R.J.; Wong, P.C. Amyloid Precursor Protein Processing and Alzheimer's Disease. Annu. Rev. Neurosci. 2011, 34, 185-204. [CrossRef]

10. Octave, J.N. The amyloid peptide precursor in Alzheimer's disease. Acta Neurol. Belg. 1995, 95, 197-209. [CrossRef] 
11. Seubert, P.; Oltersdorf, T.; Lee, M.G.; Barbour, R.; Blomquist, C.; Davis, D.L.; Bryant, K.; Fritz, L.C.; Galasko, D.; Thal, L.J.; et al. Secretion of $\beta$-amyloid precursor protein cleaved at the amino terminus of the $\beta$-amyloid peptide. Nat. Cell Biol. 1993, 361, 260-263. [CrossRef]

12. Haass, C.; Schlossmacher, M.G.; Hung, A.Y.; Vigo-Pelfrey, C.; Mellon, A.; Ostaszewski, B.L.; Lieberburg, I.; Koo, E.H.; Schenk, D.; Teplow, D.B.; et al. Amyloid $\beta$-peptide is produced by cultured cells during normal metabolism. Nat. Cell Biol. 1992, 359, 322-325. [CrossRef] [PubMed]

13. Lin, T.; Tjernberg, L.; Schedin-Weiss, S. Neuronal Trafficking of the Amyloid Precursor Protein-What Do We Really Know? BioMed 2021, 9, 801. [CrossRef]

14. LaFerla, F.M.; Green, K.N.; Oddo, S. Intracellular amyloid-beta in Alzheimer's disease. Nat. Rev. Neurosci. 2007, 8, 499-509. [CrossRef] [PubMed]

15. Esposito, Z.; Belli, L.; Toniolo, S.; Sancesario, G.; Bianconi, C.; Martorana, A. Amyloid beta, glutamate, excitotoxicity in Alzheimer's disease: Are we on the right track? CNS Neurosci. Ther. 2013, 19, 549-555. [CrossRef] [PubMed]

16. Ju, T.C.; Chen, S.D.; Liu, C.C.; Yang, D.I. Protective effects of S-nitrosoglutathione against amyloid beta-peptide neurotoxicity. Free Radic. Biol. Med. 2005, 38, 938-949. [CrossRef] [PubMed]

17. Chao, A.C.; Chen, C.H.; Wu, M.H.; Hou, B.Y.; Yang, D.I. Roles of Id1/HIF-1 and CDK5/HIF-1 in cell cycle reentry induced by amyloid-beta peptide in post-mitotic cortical neuron. Biochim. Biophys. Acta-Mol. Cell Res. 2020, 1867, 118628. [CrossRef] [PubMed]

18. Chao, A.-C.; Chen, C.-H.; Chang, S.-H.; Huang, C.-T.; Hwang, W.-C.; Yang, D.-I. Id1 and Sonic Hedgehog Mediate Cell Cycle Reentry and Apoptosis Induced by Amyloid Beta-Peptide in Post-mitotic Cortical Neurons. Mol. Neurobiol. 2018, 56, 465-489. [CrossRef]

19. Caldeira, G.L.; Ferreira, I.L.; Rego, A.C. Impaired Transcription in Alzheimer's Disease: Key Role in Mitochondrial Dysfunction and Oxidative Stress. J. Alzheimer's Dis. 2013, 34, 115-131. [CrossRef]

20. Wu, M.-F.; Yin, J.-H.; Hwang, C.-S.; Tang, C.-M.; Yang, D.-I. NAD attenuates oxidative DNA damages induced by amyloid beta-peptide in primary rat cortical neurons. Free Radic. Res. 2014, 48, 794-805. [CrossRef]

21. Vicario-Orri, E.; Opazo, C.M.; Muñoz, F.J. The Pathophysiology of Axonal Transport in Alzheimer's Disease. J. Alzheimer's Dis. 2014, 43, 1097-1113. [CrossRef]

22. Chen, X.-Q.; Sawa, M.; Mobley, W.C. Dysregulation of neurotrophin signaling in the pathogenesis of Alzheimer disease and of Alzheimer disease in Down syndrome. Free Radic. Biol. Med. 2018, 114, 52-61. [CrossRef]

23. Lauretti, E.; Praticò, D. Alzheimer's disease: Phenotypic approaches using disease models and the targeting of tau protein. Expert Opin. Ther. Targets 2020, 24, 319-330. [CrossRef] [PubMed]

24. Klein, W.L.; Krafft, G.A.; Finch, C.E. Targeting small Abeta oligomers: The solution to an Alzheimer's disease conundrum? Trends Neurosci. 2001, 24, 219-224. [CrossRef]

25. Niewiadomska, G.; Niewiadomski, W.; Steczkowska, M.; Gasiorowska, A. Tau Oligomers Neurotoxicity. Life 2021, 11, 28. [CrossRef] [PubMed]

26. Perić, A.; Annaert, W. Early etiology of Alzheimer's disease: Tipping the balance toward autophagy or endosomal dysfunction? Acta Neuropathol. 2015, 129, 363-381. [CrossRef]

27. Brewer, G.J.; Herrera, R.A.; Philipp, S.; Sosna, J.; Reyes-Ruiz, J.M.; Glabe, C.G. Age-related intraneuronal aggregation of amyloid-beta in endosomes, mitochondria, autophagosomes, and lysosomes. J. Alzheimers Dis. 2020, 73, 229-246. [CrossRef]

28. Ren, B.; Zhang, Y.; Zhang, M.; Liu, Y.; Zhang, D.; Gong, X.; Feng, Z.; Tang, J.; Chang, Y.; Zheng, J. Fundamentals of cross-seeding of amyloid proteins: An introduction. J. Mater. Chem. B 2019, 7, 7267-7282. [CrossRef] [PubMed]

29. Chen, K.L.; Yuan, R.Y.; Hu, C.J.; Hsu, C.Y. Amyloid-beta peptide alteration of tau exon-10 splicing via the GSK3beta-SC35 pathway. Neurobiol. Dis. 2010, 40, 378-385. [CrossRef]

30. Sayas, C.; Ávila, J. GSK-3 and Tau: A Key Duet in Alzheimer's Disease. Cells 2021, 10, 721. [CrossRef]

31. Budanov, A.V.; Sablina, A.A.; Feinstein, E.; Koonin, E.V.; Chumakov, P. Regeneration of Peroxiredoxins by p53-Regulated Sestrins, Homologs of Bacterial AhpD. Science 2004, 304, 596-600. [CrossRef] [PubMed]

32. Peeters, H.; Debeer, P.; Bairoch, A.; Wilquet, V.; Huysmans, C.; Parthoens, E.; Fryns, J.P.; Gewillig, M.; Nakamura, Y.; Niikawa, N.; et al. PA26 is a candidate gene for heterotaxia in humans: Identification of a novel PA26-related gene family in human and mouse. Qual. Life Res. 2003, 112, 573-580. [CrossRef]

33. Budanov, A.V.; Shoshani, T.; Faerman, A.; Zelin, E.; Kamer, I.; Kalinski, H.; Gorodin, S.; Fishman, A.; Chajut, A.; Einat, P.; et al. Identification of a novel stress-responsive gene Hi95 involved in regulation of cell viability. Oncogene 2002, 21, 6017-6031. [CrossRef] [PubMed]

34. Velasco-Miguel, S.; Buckbinder, L.; Jean, P.; Gelbert, L.; Talbott, R.; Laidlaw, J.; Seizinger, B.; Kley, N. PA26, a novel target of the p53 tumor suppressor and member of the GADD family of DNA damage and growth arrest inducible genes. Oncogene 1999, 18, 127-137. [CrossRef] [PubMed]

35. Kim, H.; An, S.; Ro, S.-H.; Teixeira, F.; Park, G.J.; Kim, C.; Cho, C.-S.; Kim, J.-S.; Jakob, U.; Lee, J.H.; et al. Janus-faced Sestrin2 controls ROS and mTOR signalling through two separate functional domains. Nat. Commun. 2015, 6, 10025. [CrossRef]

36. Saxton, R.A.; Knockenhauer, K.E.; Wolfson, R.L.; Chantranupong, L.; Pacold, M.E.; Wang, T.; Schwartz, T.U.; Sabatini, D.M. Structural basis for leucine sensing by the Sestrin2-mTORC1 pathway. Science 2015, 351, 53-58. [CrossRef] 
37. Haidurov, A.; Budanov, A.V. Sestrin family-The stem controlling healthy ageing. Mech. Ageing Dev. 2020, 192, 111379. [CrossRef] [PubMed]

38. Lee, J.H.; Budanov, A.V.; Karin, M. Sestrins Orchestrate Cellular Metabolism to Attenuate Aging. Cell Metab. 2013, 18, 792-801. [CrossRef]

39. Chen, Y.-S.; Chen, S.-D.; Wu, C.-L.; Huang, S.-S.; Yang, D.-I. Induction of sestrin2 as an endogenous protective mechanism against amyloid beta-peptide neurotoxicity in primary cortical culture. Exp. Neurol. 2014, 253, 63-71. [CrossRef]

40. Hsieh, Y.H.; Chao, A.C.; Lin, Y.C.; Chen, S.D.; Yang, D.I. The p53/NF-kappaB-dependent induction of sestrin2 by amyloid-beta peptides exerts antioxidative actions in neurons. Free Radic. Biol. Med. 2021, 169, 36-61. [CrossRef]

41. Buckbinder, L.; Talbott, R.; Seizinger, B.R.; Kley, N. Gene regulation by temperature-sensitive p53 mutants: Identification of p53 response genes. Proc. Natl. Acad. Sci. USA 1994, 91, 10640-10644. [CrossRef] [PubMed]

42. A Sablina, A.; Budanov, A.V.; Ilyinskaya, G.V.; Agapova, L.S.; E Kravchenko, J.; Chumakov, P. The antioxidant function of the p53 tumor suppressor. Nat. Med. 2005, 11, 1306-1313. [CrossRef] [PubMed]

43. Budanov, A.V.; Karin, M. p53 Target Genes Sestrin1 and Sestrin2 Connect Genotoxic Stress and mTOR Signaling. Cell 2008, 134, 451-460. [CrossRef] [PubMed]

44. Parmigiani, A.; Budanov, A. Sensing the Environment Through Sestrins: Implications for Cellular Metabolism. Pancreat. $\beta$-Cell Biol. Health Dis. 2016, 327, 1-42. [CrossRef]

45. Wolfson, R.L.; Chantranupong, L.; Saxton, R.A.; Shen, K.; Scaria, S.M.; Cantor, J.R.; Sabatini, D.M. Sestrin2 is a leucine sensor for the mTORC1 pathway. Science 2015, 351, 43-48. [CrossRef]

46. Bae, S.H.; Sung, S.H.; Oh, S.Y.; Lim, J.M.; Lee, S.K.; Park, Y.N.; Lee, H.E.; Kang, D.; Rhee, S.G. Sestrins Activate Nrf2 by Promoting p62-Dependent Autophagic Degradation of Keap1 and Prevent Oxidative Liver Damage. Cell Metab. 2013, 17, 73-84. [CrossRef]

47. The UniProt Consortium. UniProt: A worldwide hub of protein knowledge. Nucleic Acids Res. 2019, 47, D506-D515. [CrossRef]

48. Chen, M.; Xi, Y.; Chen, K.; Xiao, P.; Li, S.; Sun, X.; Han, Z. Upregulation Sestrin2 protects against hydrogen peroxide-induced oxidative damage bovine mammary epithelial cells via a Keap1-Nrf2/ARE pathway. J. Cell. Physiol. 2021, 236, 392-404. [CrossRef]

49. Shin, B.Y.; Jin, S.H.; Cho, I.J.; Ki, S.H. Nrf2-ARE pathway regulates induction of Sestrin-2 expression. Free Radic. Biol. Med. 2012, 53, 834-841. [CrossRef]

50. Olson, N.; Hristova, M.; Heintz, N.H.; Lounsbury, K.M.; Van Der Vliet, A. Activation of hypoxia-inducible factor-1 protects airway epithelium against oxidant-induced barrier dysfunction. Am. J. Physiol. Cell. Mol. Physiol. 2011, 301, L993-L1002. [CrossRef]

51. Essler, S.; Dehne, N.; Brüne, B. Role of sestrin2 in peroxide signaling in macrophages. FEBS Lett. 2009, 583, 3531-3535. [CrossRef] [PubMed]

52. Shoshani, T.; Faerman, A.; Mett, I.; Zelin, E.; Tenne, T.; Gorodin, S.; Moshel, Y.; Elbaz, S.; Budanov, A.; Chajut, A.; et al. Identification of a Novel Hypoxia-Inducible Factor 1-Responsive Gene, RTP801, Involved in Apoptosis. Mol. Cell. Biol. 2002, 22, 2283-2293. [CrossRef] [PubMed]

53. Wu, C.L.; Chen, S.D.; Yin, J.H.; Hwang, C.S.; Yang, D.I. Nuclear factor-kappaB-dependent Sestrin2 induction mediates the antioxidant effects of BDNF against mitochondrial inhibition in rat cortical neurons. Mol. Neurobiol. 2016, 53, 4126-4142. [CrossRef]

54. Liu, J.; Amar, F.; Corona, C.; So, R.; Andrews, S.J.; Nagy, P.L.; Shelanski, M.L.; Greene, L.A. Brain-Derived Neurotrophic Factor Elevates Activating Transcription Factor 4 (ATF4) in Neurons and Promotes ATF4-Dependent Induction of Sesn2. Front. Mol. Neurosci. 2018, 11, 62. [CrossRef] [PubMed]

55. Ding, B.; Parmigiani, A.; Divakaruni, A.S.; Archer, K.; Murphy, A.N.; Budanov, A.V. Sestrin2 is induced by glucose starvation via the unfolded protein response and protects cells from non-canonical necroptotic cell death. Sci. Rep. 2016, 6, 22538. [CrossRef] [PubMed]

56. Garaeva, A.; Kovaleva, I.E.; Chumakov, P.M.; Evstafieva, A.G. Mitochondrial dysfunction induces SESN2 gene expression through Activating Transcription Factor 4. Cell Cycle 2016, 15, 64-71. [CrossRef] [PubMed]

57. Wang, S.; Chen, X.A.; Hu, J.; Jiang, J.-K.; Li, Y.; Chan-Salis, K.Y.; Gu, Y.; Chen, G.; Thomas, C.; Pugh, B.F.; et al. ATF4 Gene Network Mediates Cellular Response to the Anticancer PAD Inhibitor YW3-56 in Triple-Negative Breast Cancer Cells. Mol. Cancer Ther. 2015, 14, 877-888. [CrossRef]

58. Ye, J.; Palm, W.; Peng, M.; King, B.; Lindsten, T.; Li, M.; Koumenis, C.; Thompson, C.B. GCN2 sustains mTORC1 suppression upon amino acid deprivation by inducing Sestrin2. Genes Dev. 2015, 29, 2331-2336. [CrossRef]

59. Zhang, X.-Y.; Wu, X.-Q.; Deng, R.; Sun, T.; Feng, G.-K.; Zhu, X.-F. Upregulation of sestrin 2 expression via JNK pathway activation contributes to autophagy induction in cancer cells. Cell. Signal. 2013, 25, 150-158. [CrossRef]

60. Hotamisligil, G.S. Endoplasmic Reticulum Stress and the Inflammatory Basis of Metabolic Disease. Cell 2010, 140, 900-917. [CrossRef]

61. Jegal, K.H.; Park, S.M.; Cho, S.S.; Byun, S.H.; Ku, S.K.; Kim, S.C.; Ki, S.H.; Cho, I.J. Activating transcription factor 6-dependent sestrin 2 induction ameliorates ER stress-mediated liver injury. Biochim. Biophys. Acta (BBA) Bioenerget. 2017, 1864, $1295-1307$. [CrossRef] [PubMed]

62. Park, H.-W.; Park, H.; Ro, S.-H.; Jang, I.; Semple, I.A.; Kim, D.N.; Kim, M.; Nam, M.; Zhang, D.; Yin, L.; et al. Hepatoprotective role of Sestrin2 against chronic ER stress. Nat. Commun. 2014, 5, 1-11. [CrossRef] [PubMed]

63. Lopez-Otin, C.; Blasco, M.A.; Partridge, L.; Serrano, M.; Kroemer, G. The hallmarks of aging. Cell 2013, 153, 1194-1217. [CrossRef] [PubMed] 
64. Hou, Y.; Dan, X.; Babbar, M.; Wei, Y.; Hasselbalch, S.G.; Croteau, D.L.; Bohr, V.A. Ageing as a risk factor for neurodegenerative disease. Nat. Rev. Neurol. 2019, 15, 565-581. [CrossRef]

65. Niccoli, T.; Partridge, L. Ageing as a Risk Factor for Disease. Curr. Biol. 2012, 22, R741-R752. [CrossRef]

66. Lee, J.H.; Bodmer, R.; Bier, E.; Karin, M. Sestrins at the crossroad between stress and aging. Aging 2010, 2, 369-374. [CrossRef]

67. Lee, J.H.; Budanov, A.V.; Park, E.J.; Birse, R.; Kim, T.E.; Perkins, G.A.; Ocorr, K.; Ellisman, M.H.; Bodmer, R.; Bier, E.; et al. Sestrin as a Feedback Inhibitor of TOR That Prevents Age-Related Pathologies. Science 2010, 327, 1223-1228. [CrossRef]

68. Budanov, A.V.; Lee, J.H.; Karin, M. Stressin' Sestrins take an aging fight. EMBO Mol. Med. 2010, 2, 388-400. [CrossRef] [PubMed]

69. Chen, K.-B.; Xuan, Y.; Shi, W.-J.; Chi, F.; Xing, R.; Zeng, Y.-C. Sestrin2 expression is a favorable prognostic factor in patients with non-small cell lung cancer. Am. J. Transl. Res. 2016, 8, 1903-1909.

70. Wei, J.-L.; Fu, Z.-X.; Fang, M.; Guo, J.-B.; Zhao, Q.-N.; Lu, W.-D.; Zhou, Q.-Y. Decreased expression of sestrin 2 predicts unfavorable outcome in colorectal cancer. Oncol. Rep. 2014, 33, 1349-1357. [CrossRef] [PubMed]

71. Jeong, S.; Kim, D.Y.; Kang, S.H.; Yun, H.K.; Kim, J.L.; Kim, B.R.; Park, S.H.; Na, Y.J.; Jo, M.J.; Jeong, Y.A.; et al. Docosahexaenoic Acid Enhances Oxaliplatin-Induced Autophagic Cell Death via the ER Stress/Sesn2 Pathway in Colorectal Cancer. Cancers 2019, 11, 982. [CrossRef]

72. Ro, S.-H.; Xue, X.; Ramakrishnan, S.K.; Cho, C.-S.; Namkoong, S.; Jang, I.; A Semple, I.; Ho, A.; Park, H.-W.; Shah, Y.M.; et al. Tumor suppressive role of sestrin2 during colitis and colon carcinogenesis. eLife 2016, 5, e12204. [CrossRef]

73. Lee, J.H.; Budanov, A.V.; Talukdar, S.; Park, E.J.; Park, H.L.; Park, H.-W.; Bandyopadhyay, G.; Li, N.; Aghajan, M.; Jang, I.; et al. Maintenance of Metabolic Homeostasis by Sestrin2 and Sestrin3. Cell Metab. 2012, 16, 311-321. [CrossRef] [PubMed]

74. Sundararajan, S.; Jayachandran, I.; Subramanian, S.C.; Anjana, R.M.; Balasubramanyam, M.; Mohan, V.; Venkatesan, B.; Manickam, N. Decreased Sestrin levels in patients with type 2 diabetes and dyslipidemia and their association with the severity of atherogenic index. J. Endocrinol. Investig. 2021, 44, 1395-1405. [CrossRef]

75. Mohany, K.M.; Al Rugaie, O. Association of serum sestrin 2 and betatrophin with serum neutrophil gelatinase associated lipocalin levels in type 2 diabetic patients with diabetic nephropathy. J. Diabetes Metab. Disord. 2020, 19, 249-256. [CrossRef]

76. Liao, H.-H.; Ruan, J.-Y.; Liu, H.-J.; Liu, Y.; Feng, H.; Tang, Q.-Z. Sestrin family may play important roles in the regulation of cardiac pathophysiology. Int. J. Cardiol. 2016, 202, 183-184. [CrossRef] [PubMed]

77. Liu, Y.; Li, M.; Du, X.; Huang, Z.; Quan, N. Sestrin 2, a potential star of antioxidant stress in cardiovascular diseases. Free. Radic. Biol. Med. 2021, 163, 56-68. [CrossRef] [PubMed]

78. Wang, H.; Li, N.; Shao, X.; Li, J.; Guo, L.; Yu, X.; Sun, Y.; Hao, J.; Niu, H.; Xiang, J.; et al. Increased plasma sestrin2 concentrations in patients with chronic heart failure and predicted the occurrence of major adverse cardiac events: A 36-month follow-up cohort study. Clin. Chim. Acta 2019, 495, 338-344. [CrossRef] [PubMed]

79. Boehme, A.K.; Esenwa, C.; Elkind, M.S.V. Stroke Risk Factors, Genetics, and Prevention. Circ. Res. 2017, 120, 472-495. [CrossRef] [PubMed]

80. He, T.; Li, W.; Song, Y.; Li, Z.; Tang, Y.; Zhang, Z.; Yang, G.Y. Sestrin2 regulates microglia polarization through mTOR-mediated autophagic flux to attenuate inflammation during experimental brain ischemia. J. Neuroinflamm. 2020, 17, 329. [CrossRef]

81. Li, Y.; Wu, J.; Yu, S.; Zhu, J.; Zhou, Y.; Wang, P.; Li, L.; Zhao, Y. Sestrin2 promotes angiogenesis to alleviate brain injury by activating Nrf2 through regulating the interaction between p62 and Keap1 following photothrombotic stroke in rats. Brain Res. 2020, 1745, 146948. [CrossRef] [PubMed]

82. Wang, P.; Zhao, Y.; Li, Y.; Wu, J.; Yu, S.; Zhu, J.; Li, L.; Zhao, Y. Sestrin2 overexpression attenuates focal cerebral ischemic injury in rat by increasing Nrf2/HO-1 pathway-mediated angiogenesis. Neuroscience 2019, 410, 140-149. [CrossRef] [PubMed]

83. Li, L.; Xiao, L.; Hou, Y.; He, Q.; Zhu, J.; Li, Y.; Wu, J.; Zhao, J.; Yu, S.; Zhao, Y. Sestrin2 Silencing Exacerbates Cerebral Ischemia/Reperfusion Injury by Decreasing Mitochondrial Biogenesis through the AMPK/PGC-1 $\alpha$ Pathway in Rats. Sci. Rep. 2016, 6, 30272. [CrossRef]

84. Yang, F.; Chen, R. Sestrin1 exerts a cytoprotective role against oxygen-glucose deprivation/reoxygenation-induced neuronal injury by potentiating Nrf2 activation via the modulation of Keap1. Brain Res. 2021, 1750, 147165. [CrossRef] [PubMed]

85. Johnson, M.R.; Behmoaras, J.; Bottolo, L.; Krishnan, M.L.; Pernhorst, K.; Santoscoy, P.L.M.; Rossetti, T.; Speed, D.; Srivastava, P.K.; Chadeau-Hyam, M.; et al. Systems genetics identifies Sestrin 3 as a regulator of a proconvulsant gene network in human epileptic hippocampus. Nat. Commun. 2015, 6, 1-11. [CrossRef] [PubMed]

86. Lovisari, F.; Roncon, P.; Soukoupova, M.; Paolone, G.; Labasque, M.; Ingusci, S.; Falcicchia, C.; Marino, P.; Johnson, M.; Rossetti, T.; et al. Implication of sestrin3 in epilepsy and its comorbidities. Brain Commun. 2021, 3, fcaa130. [CrossRef] [PubMed]

87. Huang, L.G.; Zou, J.; Lu, Q.C. Silencing rno-miR-155-5p in rat temporal lobe epilepsy model reduces pathophysiological features and cell apoptosis by activating Sestrin-3. Brain Res. 2018, 1689, 109-122. [CrossRef]

88. Numakawa, T.; Matsumoto, T.; Numakawa, Y.; Richards, M.; Yamawaki, S.; Kunugi, H. Protective Action of Neurotrophic Factors and Estrogen against Oxidative Stress-Mediated Neurodegeneration. J. Toxicol. 2011, 2011, 1-12. [CrossRef]

89. Niedzielska, E.; Smaga, I.; Gawlik, M.; Moniczewski, A.; Stankowicz, P.; Pera, J.; Filip, M. Oxidative Stress in Neurodegenerative Diseases. Mol. Neurobiol. 2016, 53, 4094-4125. [CrossRef]

90. Andersen, J.K. Oxidative stress in neurodegeneration: Cause or consequence? Nat. Med. 2004, 10, S18-S25. [CrossRef]

91. Thellung, S.; Corsaro, A.; Nizzari, M.; Barbieri, F.; Florio, T. Autophagy Activator Drugs: A New Opportunity in Neuroprotection from Misfolded Protein Toxicity. Int. J. Mol. Sci. 2019, 20, 901. [CrossRef]

92. Kalia, L.V.; Lang, A.E. Parkinson's disease. Lancet 2015, 386, 896-912. [CrossRef] 
93. Rocha, E.; De Miranda, B.; Sanders, L.H. Alpha-synuclein: Pathology, mitochondrial dysfunction and neuroinflammation in Parkinson's disease. Neurobiol. Dis. 2018, 109, 249-257. [CrossRef] [PubMed]

94. Del Tredici, K.; Braak, H. Review: Sporadic Parkinson's disease: Development and distribution of $\alpha$-synuclein pathology. Neuropathol. Appl. Neurobiol. 2016, 42, 33-50. [CrossRef] [PubMed]

95. Zhou, D.; Zhan, C.; Zhong, Q.; Li, S. Upregulation of sestrin-2 expression via P53 protects against 1-methyl-4-phenylpyridinium (MPP+) neurotoxicity. J. Mol. Neurosci. 2013, 51, 967-975. [CrossRef] [PubMed]

96. Hou, Y.-S.; Guan, J.-J.; Xu, H.-D.; Wu, F.; Sheng, R.; Qin, Z.-H. Sestrin2 Protects Dopaminergic Cells against Rotenone Toxicity through AMPK-Dependent Autophagy Activation. Mol. Cell. Biol. 2015, 35, 2740-2751. [CrossRef] [PubMed]

97. Rai, N.; Upadhyay, A.D.; Goyal, V.; Dwivedi, S.; Dey, A.B.; Dey, S. Sestrin2 as Serum Protein Marker and Potential Therapeutic Target for Parkinson's Disease. J. Gerontol. Ser. A: Boil. Sci. Med. Sci. 2019, 75, 690-695. [CrossRef]

98. Chen, S.-D.; Wu, C.-L.; Hwang, W.-C.; Yang, D.-I. More Insight into BDNF against Neurodegeneration: Anti-Apoptosis, AntiOxidation, and Suppression of Autophagy. Int. J. Mol. Sci. 2017, 18, 545. [CrossRef]

99. Johri, A.; Chandra, A.; Beal, M.F. PGC-1 $\alpha$, mitochondrial dysfunction, and Huntington's disease. Free Radic. Biol. Med. 2013, 62, 37-46. [CrossRef] [PubMed]

100. Tunez, I.; Tasset, I.; Perez-De La Cruz, V.; Santamaria, A. 3-Nitropropionic acid as a tool to study the mechanisms involved in Huntington's disease: Past, present and future. Molecules 2010, 15, 878-916. [CrossRef] [PubMed]

101. Wu, C.-L.; Hwang, C.-S.; Chen, S.-D.; Yin, J.; Yang, D.-I. Neuroprotective mechanisms of brain-derived neurotrophic factor against 3-nitropropionic acid toxicity: Therapeutic implications for Huntington's disease. Ann. N. Y. Acad. Sci. 2010, 1201, 8-12. [CrossRef] [PubMed]

102. Chen, S.-D.; Yang, J.-L.; Lin, T.-K.; Yang, D.-I. Emerging Roles of Sestrins in Neurodegenerative Diseases: Counteracting Oxidative Stress and Beyond. J. Clin. Med. 2019, 8, 1001. [CrossRef]

103. Celik, H.; Karahan, H.; Kelicen-Ugur, P. Effect of atorvastatin on Abeta1-42-induced alteration of SESN2, SIRT1, LC3II and TPP1 protein expressions in neuronal cell cultures. J. Pharm. Pharmacol. 2020, 72, 424-436. [CrossRef] [PubMed]

104. Rai, N.; Kumar, R.; Desai, G.R.; Venugopalan, G.; Shekhar, S.; Chatterjee, P.; Tripathi, M.; Upadhyay, A.D.; Dwivedi, S.; Dey, A.B.; et al. Relative Alterations in Blood-Based Levels of Sestrin in Alzheimer's Disease and Mild Cognitive Impairment Patients. J. Alzheimer's Dis. 2016, 54, 1147-1155. [CrossRef]

105. Reddy, K.; Cusack, C.L.; Nnah, I.C.; Khayati, K.; Saqcena, C.; Huynh, T.B.; Noggle, S.; Ballabio, A.; Dobrowolski, R. Dysregulation of Nutrient Sensing and CLEARance in Presenilin Deficiency. Cell Rep. 2016, 14, 2166-2179. [CrossRef] [PubMed]

106. Soontornniyomkij, V.; Soontornniyomkij, B.; Moore, D.J.; Gouaux, B.; Masliah, E.; Tung, S.; Vinters, H.V.; Grant, I.; Achim, C.L. Antioxidant Sestrin-2 Redistribution to Neuronal Soma in Human Immunodeficiency Virus-Associated Neurocognitive Disorders. J. Neuroimmune Pharmacol. 2012, 7, 579-590. [CrossRef]

107. Kim, J.R.; Lee, S.R.; Chung, H.J.; Kim, S.; Baek, S.H.; Kim, J.H.; Kim, Y.S. Identification of amyloid beta-peptide responsive genes by cDNA microarray technology: Involvement of RTP801 in amyloid beta-peptide toxicity. Exp. Mol. Med. 2003, 35, $403-411$. [CrossRef]

108. Tampellini, D. Synaptic activity and Alzheimer's disease: A critical update. Front. Neurosci. 2015, 9, 423. [CrossRef] [PubMed]

109. Papadia, S.; Soriano, F.; Léveillé, F.; Martel, M.-A.; A Dakin, K.; Hansen, H.H.; Kaindl, A.; Sifringer, M.; Fowler, J.; Stefovska, V.; et al. Synaptic NMDA receptor activity boosts intrinsic antioxidant defenses. Nat. Neurosci. 2008, 11, 476-487. [CrossRef] [PubMed]

110. Shen, J. Function and dysfunction of presenilin. Neurodegener. Dis. 2013, 13, 61-63. [CrossRef]

111. Sherrington, R.; Rogaev, E.I.; Liang, Y.; Rogaeva, E.A.; Levesque, G.; Ikeda, M.; Chi, H.; Lin, C.; Li, G.; Holman, K.; et al. Cloning of a gene bearing missense mutations in early-onset familial Alzheimer's disease. Nature 1995, 375, 754-760. [CrossRef]

112. Zhang, C.; Wu, B.; Beglopoulos, V.; Wines-Samuelson, M.; Zhang, D.; Dragatsis, I.; Südhof, T.C.; Shen, J. Presenilins are essential for regulating neurotransmitter release. Nat. Cell Biol. 2009, 460, 632-636. [CrossRef]

113. Zhang, L.L.; Sui, H.J.; Liang, B.; Wang, H.M.; Qu, W.H.; Yu, S.X.; Jin, Y. Atorvastatin prevents amyloid-beta peptide oligomerinduced synaptotoxicity and memory dysfunction in rats through a p38 MAPK-dependent pathway. Acta Pharmacol. Sin. 2014, 35, 716-726. [CrossRef]

114. Zhang, Q.; Yang, Y.-J.; Wang, H.; Dong, Q.-T.; Wang, T.-J.; Qian, H.-Y.; Xu, H. Autophagy Activation: A Novel Mechanism of Atorvastatin to Protect Mesenchymal Stem Cells from Hypoxia and Serum Deprivation via AMP-Activated Protein Kinase/Mammalian Target of Rapamycin Pathway. Stem Cells Dev. 2012, 21, 1321-1332. [CrossRef] [PubMed]

115. Arancibia, S.; Silhol, M.; Mouliere, F.; Meffre, J.; Höllinger, I.; Maurice, T.; Tapia-Arancibia, L. Protective effect of BDNF against beta-amyloid induced neurotoxicity in vitro and in vivo in rats. Neurobiol. Dis. 2008, 31, 316-326. [CrossRef]

116. Nagahara, A.H.; Merrill, D.; Coppola, G.; Tsukada, S.; E Schroeder, B.; Shaked, G.M.; Wang, L.; Blesch, A.; Kim, A.; Conner, J.M.; et al. Neuroprotective effects of brain-derived neurotrophic factor in rodent and primate models of Alzheimer's disease. Nat. Med. 2009, 15, 331-337. [CrossRef]

117. Du, Y.; Ma, X.; Ma, L.; Li, S.; Zheng, J.; Lv, J.; Cui, L.; Lv, J. Inhibition of microRNA-148b-3p alleviates oxygen-glucose deprivation/reoxygenation-induced apoptosis and oxidative stress in HT22 hippocampal neuron via reinforcing Sestrin2/Nrf2 signalling. Clin. Exp. Pharmacol. Physiol. 2020, 47, 561-570. [CrossRef] [PubMed] 
118. Fan, Y.; Xing, Y.; Xiong, L.; Wang, J. Sestrin2 overexpression alleviates hydrogen peroxide-induced apoptosis and oxidative stress in retinal ganglion cells by enhancing Nrf2 activation via Keap1 downregulation. Chem. Interact. 2020, 324, 109086. [CrossRef] [PubMed]

119. Huang, L.-K.; Chao, S.-P.; Hu, C.-J. Clinical trials of new drugs for Alzheimer disease. J. Biomed. Sci. 2020, 27, 1-13. [CrossRef] [PubMed]

120. Khan, A.; Corbett, A.; Ballard, C. Emerging treatments for Alzheimer's disease for non-amyloid and non-tau targets. Expert Rev. Neurother. 2017, 17, 683-695. [CrossRef]

121. Nabirotchkin, S.; E Peluffo, A.; Rinaudo, P.; Yu, J.; Hajj, R.; Cohen, D. Next-generation drug repurposing using human genetics and network biology. Curr. Opin. Pharmacol. 2020, 51, 78-92. [CrossRef] [PubMed]

122. Ashburn, T.T.; Thor, K.B. Drug repositioning: Identifying and developing new uses for existing drugs. Nat. Rev. Drug Discov. 2004, 3, 673-683. [CrossRef]

123. Yang, J.-L.; Yang, Y.-R.; Chen, S.-D. The potential of drug repurposing combined with reperfusion therapy in cerebral ischemic stroke: A supplementary strategy to endovascular thrombectomy. Life Sci. 2019, 236, 116889. [CrossRef]

124. Ballard, C.; Aarsland, D.; Cummings, J.; O’Brien, J.; Mills, R.; Molinuevo, J.L.; Fladby, T.; Williams, G.; Doherty, P.; Corbett, A.; et al. Drug repositioning and repurposing for Alzheimer disease. Nat. Rev. Neurol. 2020, 16, 661-673. [CrossRef]

125. Ihara, M.; Saito, S. Drug Repositioning for Alzheimer's Disease: Finding Hidden Clues in Old Drugs. J. Alzheimer's Dis. 2020, 74, 1013-1028. [CrossRef]

126. Singh, R.K. Recent Trends in the Management of Alzheimer's Disease: Current Therapeutic Options and Drug Repurposing Approaches. Curr. Neuropharmacol. 2020, 18, 868-882. [CrossRef] [PubMed]

127. Dunkel, P.; Chai, C.; Sperlágh, B.; Huleatt, P.B.; Mátyus, P. Clinical utility of neuroprotective agents in neurodegenerative diseases: Current status of drug development for Alzheimer's, Parkinson's and Huntington's diseases, and amyotrophic lateral sclerosis. Expert Opin. Investig. Drugs 2012, 21, 1267-1308. [CrossRef]

128. Sun, X.; Han, F.; Lu, Q.; Li, X.; Ren, D.; Zhang, J.; Han, Y.; Xiang, Y.K. Empagliflozin ameliorates obesity-related cardiac dysfunction by regulating Sestrin2-mediated AMPK-mTOR signaling and redox homeostasis in high-fat diet-induced obese mice. Diabetes 2020, 69, 1292-1305. [CrossRef] [PubMed]

129. Han, X.; Ding, C.; Zhang, G.; Pan, R.; Liu, Y.; Huang, N.; Hou, N.; Han, F.; Xu, W.; Sun, X. Liraglutide ameliorates obesity-related nonalcoholic fatty liver disease by regulating Sestrin2-mediated Nrf2/HO-1 pathway. Biochem. Biophys. Res. Commun. 2020, 525, 895-901. [CrossRef] [PubMed]

130. Entezar-Almahdi, E.; Mohammadi-Samani, S.; Tayebi, L.; Farjadian, F. Recent Advances in Designing 5-Fluorouracil Delivery Systems: A Stepping Stone in the Safe Treatment of Colorectal Cancer. Int. J. Nanomed. 2020, 15, 5445-5458. [CrossRef]

131. Vodenkova, S.; Buchler, T.; Cervena, K.; Veskrnova, V.; Vodicka, P.; Vymetalkova, V. 5-fluorouracil and other fluoropyrimidines in colorectal cancer: Past, present and future. Pharmacol. Ther. 2020, 206, 107447. [CrossRef]

132. Seo, K.; Ki, S.H.; Park, E.Y.; Shin, S.M. 5-Fluorouracil inhibits cell migration by induction of Sestrin2 in colon cancer cells. Arch. Pharmacal Res. 2016, 40, 231-239. [CrossRef]

133. Brüning, A.; Rahmeh, M.; Friese, K. Nelfinavir and bortezomib inhibit mTOR activity via ATF4-mediated sestrin-2 regulation. Mol. Oncol. 2013, 7, 1012-1018. [CrossRef]

134. Lan, X.; Kiyota, T.; Hanamsagar, R.; Huang, Y.; Andrews, S.; Peng, H.; Zheng, J.C.; Swindells, S. The effect of HIV protease inhibitors on amyloid-beta peptide degradation and synthesis in human cells and Alzheimer's disease animal model. J. Neuroimmune Pharmacol. 2012, 7, 412-423. [CrossRef] [PubMed]

135. Lee, S.; Byun, J.; Park, M.; Kim, S.W.; Lee, S.; Kim, J.; Lee, I.; Choi, Y.; Park, K. Melatonin inhibits vascular smooth muscle cell proliferation and apoptosis through upregulation of Sestrin2. Exp. Ther. Med. 2020, 19, 3454-3460. [CrossRef] [PubMed]

136. Seo, K.; Seo, S.; Han, J.Y.; Ki, S.H.; Shin, S.M. Resveratrol attenuates methylglyoxal-induced mitochondrial dysfunction and apoptosis by Sestrin2 induction. Toxicol. Appl. Pharmacol. 2014, 280, 314-322. [CrossRef] [PubMed]

137. Jin, S.H.; Yang, J.H.; Shin, B.Y.; Seo, K.; Shin, S.M.; Cho, I.J.; Ki, S.H. Resveratrol inhibits LXRalpha-dependent hepatic lipogenesis through novel antioxidant Sestrin2 gene induction. Toxicol. Appl. Pharmacol. 2013, 271, 95-105. [CrossRef]

138. Galiniak, S.; Aebisher, D.; Bartusik-Aebisher, D. Health benefits of resveratrol administration. Acta Biochim. Pol. 2019, 66, 13-21. [CrossRef]

139. Del Rio, D.; Rodriguez-Mateos, A.; Spencer, J.P.E.; Tognolini, M.; Borges, G.; Crozier, A. Dietary (Poly)phenolics in Human Health: Structures, Bioavailability, and Evidence of Protective Effects Against Chronic Diseases. Antioxid. Redox Signal. 2013, 18, 1818-1892. [CrossRef]

140. Sun, A.Y.; Wang, Q.; Simonyi, A.; Sun, G.Y. Resveratrol as a Therapeutic Agent for Neurodegenerative Diseases. Mol. Neurobiol. 2010, 41, 375-383. [CrossRef]

141. Malaguarnera, L. Influence of Resveratrol on the Immune Response. Nutrients 2019, 11, 946. [CrossRef]

142. Singh, A.P.; Singh, R.; Verma, S.S.; Rai, V.; Kaschula, C.H.; Maiti, P.; Gupta, S.C. Health benefits of resveratrol: Evidence from clinical studies. Med. Res. Rev. 2019, 39, 1851-1891. [CrossRef]

143. Allaman, I.; Belanger, M.; Magistretti, P.J. Methylglyoxal, the dark side of glycolysis. Front. Neurosci. 2015, 9, 23. [CrossRef] [PubMed]

144. Lou, Y.; Wu, J.; Liang, J.; Yang, C.; Wang, K.; Wang, J.; Guo, X. Eupatilin protects chondrocytes from apoptosis via activating sestrin2-dependent autophagy. Int. Immunopharmacol. 2019, 75, 105748. [CrossRef] 
145. Jegal, K.H.; Ko, H.L.; Park, S.M.; Byun, S.H.; Kang, K.W.; Cho, I.J.; Kim, S.C. Eupatilin induces Sestrin2-dependent autophagy to prevent oxidative stress. Apoptosis 2016, 21, 642-656. [CrossRef] [PubMed]

146. Du, J.-X.; Wu, J.-Z.; Li, Z.; Zhang, C.; Shi, M.-T.; Zhao, J.; Jin, M.-W.; Liu, H. Pentamethylquercetin protects against cardiac remodeling via activation of Sestrin2. Biochem. Biophys. Res. Commun. 2019, 512, 412-420. [CrossRef] [PubMed]

147. Yang, J.H.; Shin, B.Y.; Han, J.Y.; Kim, M.G.; Wi, J.E.; Kim, Y.W.; Cho, I.J.; Kim, S.C.; Shin, S.M.; Ki, S.H. Isorhamnetin protects against oxidative stress by activating Nrf2 and inducing the expression of its target genes. Toxicol. Appl. Pharmacol. 2014, 274, 293-301. [CrossRef] [PubMed]

148. Salehi, B.; Sharopov, F.; Fokou, P.V.T.; Kobylinska, A.; De Jonge, L.; Tadio, K.; Sharifi-Rad, J.; Posmyk, M.M.; Martorell, M.; Martins, N.; et al. Melatonin in Medicinal and Food Plants: Occurrence, Bioavailability, and Health Potential for Humans. Cells 2019, 8, 681. [CrossRef] [PubMed]

149. Tordjman, S.; Chokron, S.; Delorme, R.; Charrier, A.; Bellissant, E.; Jaafari, N.; Fougerou, C. Melatonin: Pharmacology, Functions and Therapeutic Benefits. Curr. Neuropharmacol. 2017, 15, 434-443. [CrossRef] 